\title{
Trans-Atlantic Equity Volatility Connectedness: U.S. and European Financial Institutions, 2004-2014
}

\author{
FRANCIS X. DiEBOLD \\ University of Pennsylvania \\ KAMIL YILMAZ \\ Koç University
}

\begin{abstract}
We characterize equity return volatility connectedness in the network of major American and European financial institutions, 2004-2014. Our methods enable precise characterization of the timing and evolution of key aspects of the financial crisis. First, we find that during 2007-2008 the direction of connectedness was clearly from the United States to Europe, but that connectedness became bidirectional starting in late 2008. Second, we find an unprecedented surge in directional connectedness from European to U.S. financial institutions in June 2011, consistent with massive deterioration in the health of EU financial institutions. Third, we identify particular institutions that played disproportionately important roles in generating connectedness during the U.S. and the European crises.
\end{abstract}

KEYWORDS: network connectedness, systemic risk, systemically important financial institutions, variance decomposition, vector autoregression

(JEL: C32, G21)

The Great Crisis of 2007-2011 struck the global financial system more forcefully than any other in recent history, starting in the U.S. sub-prime mortgage market and progressing through several stages lasting a year and a half. Then it went global in late 2008, affecting many countries and markets, producing a global recession and a sharp global trade contraction in 2009. Peripheral EU countries were hit

For constructive comments and guidance we thank the Editor (Eric Ghysels) and two anonymous referees, as well as Mert Demirer, Domenico Giannone, Laura Liu, Matteo Luciani, and David Veradas, and seminar participants at ECARES, Koc, and Penn. Deniz Gok and Engin Iyidogan provided fine research assistance. The Scientific and Technological Research Council of Turkey (TUBITAK) provided financial support through Grant No. 111K500. The usual disclaimer applies. Address correspondence to Francis X. Diebold, University of Pennsylvania, or e-mail: fdiebold@sas.upenn.edu 
particularly hard in 2010-2011, with not only many financial institutions, but also several governments, approaching bankruptcy.

This background makes clear that understanding financial institution connectedness is key for understanding financial crises and their evolution. In this article, we contribute to such an understanding with a detailed study of connectedness both within and between U.S. and European financial institutions, 2004-2014, a period that includes all phases of the Great Crisis. Our analysis and results range from the granular (pairwise connectedness of individual institutions) to the aggregative (total system-wide connectedness), and from static (unconditional, or "average," connectedness over the full sample) to dynamic (conditional connectedness and its movements during particular episodes).

Our contribution is unabashedly empirical rather than methodological, as we have developed the underlying methodological econometric framework in a series of earlier papers Diebold and Yilmaz 2009. Diebold and Yilmaz 2012; Diebold and Yilmaz 2014) as unified in Diebold and Yilmaz (2015). The new contribution, then, is the substantive exploration, based on a new dataset that includes financial institutions on both sides of the Atlantic. The results complement and significantly extend Diebold and Yilmaz 2014), who studied only U.S. financial institutions and so could say nothing about trans-Atlantic linkages, despite their importance as the crisis progressed globally.

Among other things, we document and quantify clear shifts in the direction of net-connectedness as the crisis unfolded. Early on, as fear gripped the United States markets in 2007-2008, the direction was clearly from the United States to Europe. (i.e., in a sense that we will shortly make precise, the United States was a clear net exporter of future uncertainty to Europe.) Then, starting in late 2008 as Lehman Brothers failed and Europe became embroiled in the crisis, connectedness became much more equally bidirectional. Finally, later in 2011 as the health of EU financial institutions deteriorated, the balance tipped the other way; we document an unprecedented surge in net directional connectedness from European to U.S. financial institutions.

We proceed as follows. In Section 1 we summarize our approach and the range-based stock-return volatility data on which we base our connectedness measurement. In Section 2 we perform a full-sample (static) analysis, in which we effectively characterize average, or unconditional, connectedness across financial institutions. This is of intrinsic interest, and it also sets the stage for Section 3 where we perform a rolling-sample (dynamic) analysis of conditional connectedness. In Section 4 we "zoom in" on pairwise connectedness on some critical days, and we conclude in Section 5

\section{FINANCIAL INSTITUTION CONNECTEDNESS MEASUREMENT: FRAMEWORK AND DATA}

In this section we do two things. First we introduce our connectedness measurement framework. We are extremely brief and describe only population aspects because, 
unless stated otherwise, the framework and associated empirical implementation are precisely as in Diebold and Yilmaz 2014, to which we refer the reader for details. Second, we introduce the U.S. and European financial-firm return volatilities whose connectedness we study.

\subsection{The Basic Framework}

We build connectedness measures from the variance decomposition matrix of a vector-autoregressive approximating model. In particular, consider a covariance stationary $N$-variable $\operatorname{VAR}(p), x_{t}=\sum_{i=1}^{p} \Phi_{i} x_{t-i}+\varepsilon_{t}$, where $\varepsilon_{t} \sim(0, \Sigma)$. The moving average representation is $x_{t}=\sum_{i=0}^{\infty} A_{i} \varepsilon_{t-i}$, where the $N \times N$, coefficient matrices $A_{i}$ obey the recursion $A_{i}=\Phi_{1} A_{i-1}+\Phi_{2} A_{i-2}+\ldots+\Phi_{p} A_{i-p}$, with $A_{0}$ an $N \times N$ identity matrix and $A_{i}=0$ for $i<0$. The moving-average coefficients are the key to understanding dynamics. We rely on variance decompositions, which are transformations of the moving-average coefficients, and which allow us to split the $H$-step-ahead forecast error variances of each variable into parts attributable to the various system shocks.

Calculation of variance decompositions often proceeds via precise orthogonalization of VAR shocks. Cholesky factor and structural VAR identification schemes achieve orthogonality, for example, but variance decompositions then depend on the ordering of the variables (in the Cholesky case) or the maintained assumption of one or another theory (in the structural VAR case), which makes them unattractive. Hence we use the generalized approach of Koop, Pesaran, and Potten 1996) and Pesaran and Shin 1998), which allows for correlated shocks but accounts for them appropriately.

Variable $j$ 's contribution to variable $i$ 's $H$-step-ahead generalized forecast error variance is:

$$
\theta_{i j}^{g}(H)=\frac{\sigma_{j j}^{-1} \sum_{h=0}^{H-1}\left(e_{i}^{\prime} A_{h} \Sigma e_{j}\right)^{2}}{\sum_{h=0}^{H-1}\left(e_{i}^{\prime} A_{h} \Sigma A_{h}^{\prime} e_{i}\right)},
$$

where $\sigma_{j j}$ is the standard deviation of $\varepsilon_{j}$, and $e_{i}$ is the selection vector with $i$ th element unity and zeros elsewhere. Because the row sums of the variance decomposition matrix (the matrix with $i j$-th element 11) are not necessarily unity (i.e., $\sum_{j=1}^{N} \theta_{i j}^{g}(H) \neq 1$ ) we normalize each entry by the row sum, producing

$$
\tilde{\theta}_{i j}^{g}(H)=\frac{\theta_{i j}^{g}(H)}{\sum_{j=1}^{N} \theta_{i j}^{g}(H)} .
$$

Now $\sum_{j=1}^{N} \tilde{\theta}_{i j}^{g}(H)=1$ and $\sum_{i, j=1}^{N} \tilde{\theta}_{i j}^{g}(H)=N$, by construction. $\tilde{\theta}_{i j}^{g}(H)$ provides a natural and immediate measure of pairwise directional connectedness from $j$ to $i$ at horizon $H$, and in a more informative and slightly less-cluttered notation we write $C_{i \leftarrow j}(H)$. Sometimes we will also be interested in net pairwise directional connectedness, $C_{i j}(H)=C_{i \leftarrow j}(H)-C_{j \leftarrow i}(H)$. 
Next, we can aggregate partially to arrive at "total directional connectedness." There are two versions, "from" and "to." In an obvious notation, we have:

$$
C_{i \leftarrow \bullet}(H)=\frac{\sum_{\substack{j=1 \\ j \neq i}}^{N} \tilde{\theta}_{i j}^{g}(H)}{\sum_{i, j=1}^{N} \tilde{\theta}_{i j}^{g}(H)} \times 100=\frac{\sum_{\substack{j=1 \\ j \neq i}}^{N} \tilde{\theta}_{i j}^{g}(H)}{N} \times 100
$$

and

$$
C_{\bullet \leftarrow i}(H)=\frac{\sum_{\substack{j=1 \\ j \neq i}}^{N} \tilde{\theta}_{j i}^{g}(H)}{\sum_{i, j=1}^{N} \tilde{\theta}_{j i}^{g}(H)} \times 100=\frac{\sum_{\substack{j=1 \\ j \neq i}}^{N} \tilde{\theta}_{j i}^{g}(H)}{N} \times 100 .
$$

Sometimes we will be interested in net total directional connectedness, $C_{i}(H)=$ $\mathrm{C}_{\bullet \leftarrow i}(H)-\mathrm{C}_{i \leftarrow \bullet}(H)$.

Finally, we can aggregate completely to arrive at "total connectedness," or "system-wide connectedness":

$$
C(H)=\frac{\sum_{\substack{i, j=1 \\ i \neq j}}^{N} \tilde{\theta}_{i j}^{g}(H)}{\sum_{i, j=1}^{N} \tilde{\theta}_{i j}^{g}(H)}=\frac{\sum_{\substack{i, j=1 \\ i \neq j}}^{N} \tilde{\theta}_{i j}^{g}(H)}{N} .
$$

System-wide connectedness is the ratio of the sum of the off-diagonal elements of the variance decomposition matrix to the sum of all its elements.

Although all of our connectedness measures were proposed and motivated directly, it turns out that they are intimately related to the most well-known and fundamental description of overall network topology, the degree distribution, and similarly, to the most well-known and fundamental measure of network connectedness, the mean degree. One simply interprets the variance decomposition matrix as the adjacency matrix of a weighted directed network. Then the elements of the adjacency matrix are our pairwise directional connectedness, $C_{i \leftarrow j}(H)$; the row sums of the adjacency matrix (node in-degrees) are our total directional connectedness "from", $C_{i \leftarrow \bullet}(H)$; the column sums of the adjacency matrix (node out-degrees) are our total directional connectedness "to", $C_{\bullet} \leftarrow i(H)$; and the mean degree is our systemwide connectedness, $\mathrm{C}(H)$. Hence our connectedness measures are on especially firm footing, as emphasized in Diebold and Yilmaz 2014).

In closing this section we briefly mention some of the most closely-related literature. Billioet al. 2012) focus on pairwise Granger causality, which is related to our pairwise directional connectedness. Engle and Kelly 2012 effectively focus on average pairwise correlation, which is related to our systemwide connectedness. The CoVaR approach of Adrian and Brunnermeien 2008) and the marginal expected shortfall (MES) approach of Acharya, Pedersen, Philippe, and Richardson 2010 track association between individual-firm and overall-market movements, in one direction or the other. Hence they are related to our total directional connectedness; MES 
parallels our total directional connectedness "from" and CoVaR parallels our total directional connectedness "to". Perhaps most closely related is the approach of Bonaldi, Hortaçsu, and Kast 2015), which interprets a first-order VAR coefficient matrix as the adjacency matrix of a weighted, directed network and calculates various connectedness measures. A key difference is that our approach recognizes that connectedness arises not only through the cross-variable dependence captured in VAR coefficients, but also through the shock dependence captured in the VAR disturbance covariance matrix 1

\subsection{Financial Institution Stock Return Volatilities}

Financial institutions (FIs) are connected directly through counter-party linkages associated with positions in various assets, through contractual obligations associated with services provided to clients and other institutions, and through deals recorded in their balance sheets. High-frequency analysis of FI connectedness therefore might seem to require high-frequency balance sheet and related information, which is generally unavailable.

Fortunately, however, data on stock returns and return volatilities are available, which reflect forward-looking assessments of many thousands of smart, strategic and often privately-informed agents as regards precisely the relevant sorts of connections. We therefore use the available stock returns and return volatilities data to measure connectedness and its evolution. It is important to note that we remain agnostic as to how connectedness arises; rather, we take it as given and seek to measure it correctly, consistent with a wide range of possible underlying causal structures.

We focus on volatility connectedness, for at least two reasons. First, if volatility tracks investor fear (e.g., the VIX is often touted as an "investor fear gauge"), then volatility connectedness is the "fear connectedness" expressed by market participants as they trade. We are interested in the level, variation, paths, patterns, and clustering in such fear connectedness. Second, volatility connectedness is of special interest because we are particularly interested in crises, and volatility is particularly crisis-sensitive.

Volatility is latent, however, and hence must be estimated. We use rangebased volatility, which has received significant attention in recent years 2 Following Garman and Klass 1980, we construct a daily range-based volatility estimate, for a given FI on a given day, as

$$
\tilde{\sigma}^{2}=0.511(h-l)^{2}-0.019[(c-o)(h+l-2 o)-2(h-o)(l-o)]-0.383(c-o)^{2},
$$

\footnotetext{
${ }^{1}$ This is also a key distinction between our pairwise connectedness and the Granger-causal connectedness of Billio et al. 2012.

${ }^{2}$ On range-based volatility, see, for example, Alizadeh, Brandt, and Diebold 2002. For a broad volatility survey see Andersen, Bollerslev, Christoffersen, and Diebold 2013.
} 
Table 1 U.S. Financial institution detail

\begin{tabular}{lcccc}
\hline & & \multicolumn{2}{c}{ Market Cap. } & Assets \\
\cline { 2 - 3 } Institution & Ticker & $12 / 29 / 06$ & $5 / 30 / 14$ & $3 / 31 / 14$ \\
\hline JP Morgan Chase & JPM & 169 & 210 & 2477 \\
Bank of America & BAC & 241 & 159 & 2150 \\
Citigroup & C & 274 & 145 & 1895 \\
Wells Fargo & WFC & 121 & 267 & 1547 \\
Goldman Sachs & GS & 86 & 71 & 916 \\
Morgan Stanley & MS & 85 & 61 & 831 \\
US Bancorp & USB & 64 & 77 & 371 \\
Bank NY Mellon & BK & 30 & 39 & 368 \\
PNC Financial & PNC & 22 & 46 & 323 \\
American Express & AXP & 74 & 97 & 151 \\
Fannie Mae & FNM & 59 & 1.3 & \\
Freddie Mac & FRE & 47 & 0.9 & 547 \\
AIG & AIG & 187 & 4 & $9 / 15 / 08$ \\
Bear Stearns & BSC & 19 & Acquired by JPM $3 / 17 / 08$ \\
Lehman Brothers & LEH & 41 & Bankruptcy & 9608 \\
Merrill Lynch & MER & 82 & Acquired by BAC $9 / 15 / 08$ \\
Wachovia Bank & WB & 115 & Acquired by WFC $10 / 3 / 08$ \\
\hline
\end{tabular}

Notes: Market capitalizations and assets are in billions of U.S. dollars.

where the log daily high price is $h$, the $\log \operatorname{low}$ is $l$, the $\log$ opening is $o$, and the $\log$ close is $c$.

We study daily stock return volatilities of 35 major FIs, 18 European and 17 United States, January 2004 to June 2014. The European sample consists entirely of commercial banks. Although the U.S. sample covers almost all important North American FIs, the EU sample is not complete without Switzerland. Hence, despite Switzerland's absence from the EU, we include two globally important Swiss FIs (UBS and Credit Suisse) in the analysis.

The U.S. sample includes seven commercial banks, two investment banks, and one credit card company. It also includes stocks of seven FIs that were either acquired by another instution (Bear Stearns, Merrill Lynch, and Wachovia Bank), went bankrupt (Lehman Brothers), or taken under government custody (Fannie Mae, Freddie Mac, and AIG) 3

The vast majority of the included FIs, whether U.S. or European, are classified as Global Systemically Important Banks (G-SIBs). Of twenty-eight banks in the fullsample, only six (three from the United States, three from the EU) are not included in the G-SIBs list announced by the Financial Stability Board on November 1, 2012.

\footnotetext{
${ }^{3}$ We include those stocks from the beginning of the sample until the time they went bankrupt, were taken over by another private FI, or taken into government custody.
} 
Table 2 European financial institution detail

\begin{tabular}{lccccc}
\hline & & & \multicolumn{2}{c}{ Market Cap. } & Assets \\
\cline { 3 - 4 } Institution & Ticker & Country & $12 / 29 / 06$ & $5 / 30 / 14$ & $3 / 31 / 14$ \\
\hline Dexia & DEX & Belgium & 31 & 0.1 & 473 \\
KBC & KBC & & 45 & 25 & 339 \\
Deutsche Bank & DBK & Germany & 70 & 41 & 2254 \\
Commerzbank & CBK & & 25 & 18 & 791 \\
BNP Paribas & BNP & France & 101 & 87 & 2,593 \\
Societe Generale & GLE & & 79 & 46 & 1743 \\
Credit Agricole & ACA & & 63 & 39 & 2139 \\
Unicredit Group & UCG & Italy & 91 & 51 & 1159 \\
Intesa San Paolo & ISP & & 46 & 52 & 861 \\
ING Bank & ING & Netherlands & 98 & 54 & 1306 \\
Bank Santander & SAN & Spain & 117 & 121 & 1610 \\
BBVA & BBVA & & 85 & 76 & 825 \\
UBS & UBS & Switzerland & 128 & 77 & 993 \\
Credit Suisse Group & CSG & & 85 & 48 & 1111 \\
HSBC & HSBA & UK & 211 & 201 & 2758 \\
Barclays & BARC & & 93 & 68 & 2272 \\
Royal B. Scotland & RBS & & 123 & 36 & 1708 \\
Lloyds Bank & LLOY & & 63 & 93 & 1405 \\
\hline
\end{tabular}

Notes: Market capitalizations and assets are in billions of U.S. dollars.

In Tables 1 and 2 we show the U.S. and European FIs, respectively, along with their stock tickers, stock market capitalization pre-crisis (December 2006) and postcrisis (March 2014), and total assets as of March 2014. The market capitalization of all included U.S. FIs declined substantially during the global financial crisis. Since the end of the global financial crisis in the first half of 2009, however, their stock prices recovered some of the lost ground. As a result, market capitalizations of 6 out of 10 U.S. FIs on May 30, 2014 were either above or very close to their corresponding market capitalizations on December 29, 2006. The exceptions are Bank of America, Citigroup, Goldman Sachs and Morgan Stanley, all of which suffered substantially during the crisis.

\section{STATIC (FULL-SAMPLE, UNCONDITIONAL) ANALYSIS}

In this section, we analyze the full-sample, static, unconditional volatility connectedness among the largest FIs on the two sides of the Atlantic. First, we analyze connectedness among FIs, and then we undertake a detailed analysis of connectedness among country banking systems.

Volatilities tend to be distributed asymmetrically, with a right skew, and approximate normality is often obtained by taking natural logarithms, as 


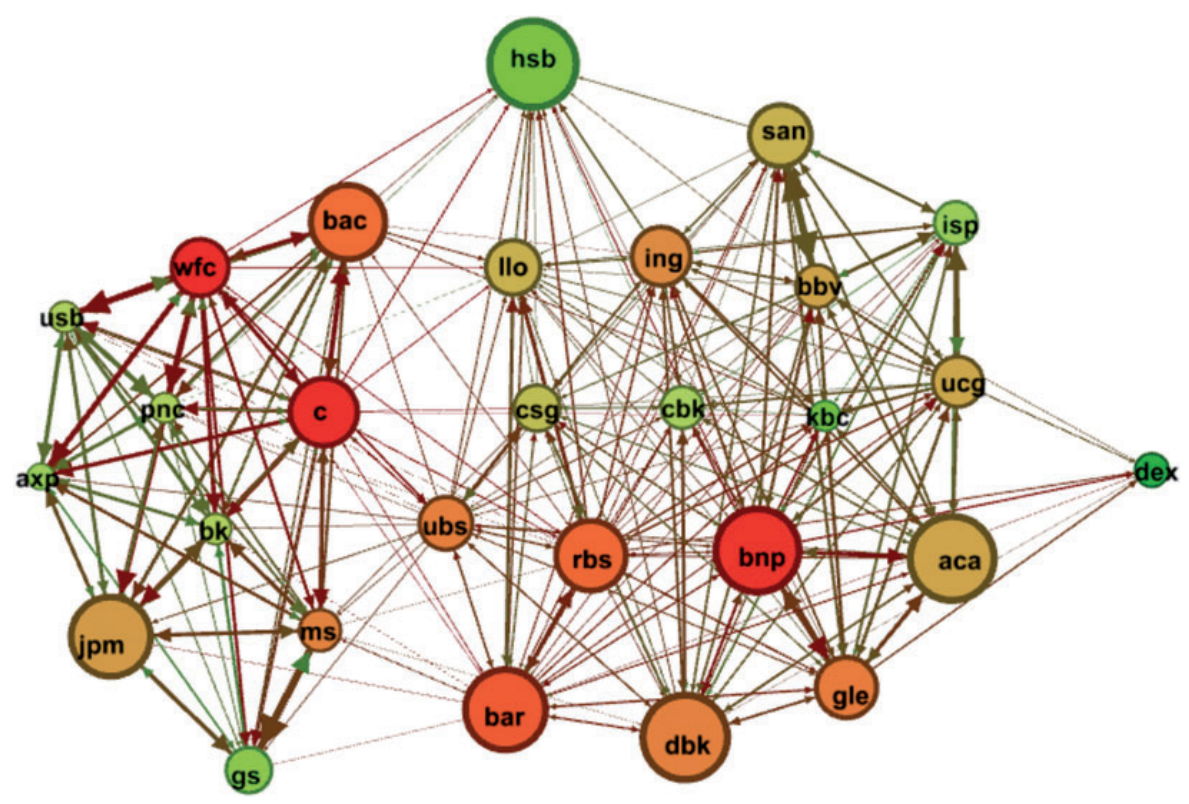

Figure 1 FI Network across the Atlantic based on pairwise directional volatility connectedness over the full-sample, from January 2, 2004 to May 30, 2014.

emphasized in Andersen, Bollerslev, Diebold, and Labys 2003). Hence we work with $\log$ volatilities. We use predictive horizon $H=12$ days. We include all European institutions, but only those U.S. institutions that survived the crisis. Finally, volatilities tend to be strongly serially correlated-much more so than returns, particularly when observed at our daily frequency—and we capture such serial correlation using third-order vector-autoregressive approximating models 4

We rely heavily on graphical display for understanding the structure of connectedness, using node colors, etc., to convey information about estimated network characteristics 5 Node size indicates asset size; node color indicates total directional connectedness "to others"; node location indicates average pairwise directional connectedness (close nodes have high average pairwise directional connectedness; edge thickness also indicates average pairwise directional connectedness; edge arrow sizes indicate pairwise directional connectedness "to" and "from."

Figure1 1presents the full-sample static volatility connectedness (network) plot. The nodes represent the twenty-eight FI stocks included in our analysis. The size

\footnotetext{
${ }^{4}$ Unrestricted high-dimensional VAR's admittedly produce rather profligate parameterizations, as large numbers of parameters must be estimated. In future work, we look forward to incorporating various strategies for high-dimensional shrinkage and selection, and/or formal models of time-varying highdimensional parameters. The "fused lasso" of Tibshirani, Saunders, Rosset, Zhu, and Knigh 2005), as explored in Liu 2015), is a promising choice that blends both.

${ }^{5}$ We use the open-source Gephi (https://gephi.github.io/. last accessed October 31, 2015) software to visualize large network graphs.
} 
of each node indicates the asset size of the corresponding FI as of the end of March 31, 2014 (see Tables 1 and 2). The color of each node indicates the size of the total volatility connectedness of the FI stock "to" others (from black (strongest) to dark gray, and light gray (weakest)) 6

When we consider the full-sample, the European and the U.S. FIs form two groups as if separated by the Atlantic Ocean. Two U.S. FIs, Citigroup and Wells Fargo, and one European FI, BNP Paribas, have the highest total volatility connectedness "to" others as indicated by their black (red) colored nodes. They were followed by Bank of America, Barclays, and the Royal Bank of Scotland whose nodes are orange colored, and UBS, Deutsche Bank, Societe Generale, ING, J.P. Morgan and Morgan Stanley with dark gray (brown) colored nodes.

The respective locations of Citigroup and BAC, UBS and Barclays reveal that they are the ones that generated highest "to" connectedness to their counterparts across the Atlantic. The respective locations and node colors of Lloyds, Credit Suisse, and HSBC, on the other hand, indicates that these FIs are the ones that received highest volatility connectedness across the Atlantic.

Among the European FIs, BBVA, Lloyds, Credit Agricole, Santander, and Unicredit have lower connectedness "to" others as indicated by their light gray (brown) colored nodes. The remaining five of the U.S. FIs have lower "to" connectedness as indicated by their lighter gray (green) colored nodes. Among the European FIs Dexia, HSBC, KBC, Intesa San Paola, and Commerzbank had the lowest volatility connectedness "to" others. Their nodes are all in light gray (green).

HSBC and Dexia are located further away from other FIs stocks. HSBC is the largest FI in terms of asset size. Yet, it has very low "to" volatility connectedness when we consider the full sample. That is so, because HSBC had weathered the global financial crisis better than other global FIs. However, as we will see later there were moments when HSBC had hard times as well. Dexia, on the other hand, was one of the worst performing FIs during and after the global financial crisis. As it was moving toward bankruptcy it was taken into the custody of the Belgian government. Since then its stock moved more or less independent from others.

In Figure 2 we present the "net" connectedness plots. The edges between nodes have only one-way: it is equal to the net pairwise connectedness measures between the two nodes. The net pairwise connectedness plot is consistent with the one we obtained for pairwise connectedness measures. There is still a land-divide between the U.S. and European FIs.

Wells Fargo and Citigroup are the two FIs with the highest net-connectedness to others, slightly above $20 \%$, followed by BNP Paribas, $17.1 \%$, Barclays, $15.6 \%$, Royal Bank of Scotland, 14.9\%, and Bank of America, 12.3\%. The net-connectedness of UBS, Morgan Stanley, Societe Generale, Deutsche Bank, and ING range from $10.5 \%$ to all the way down to $6.1 \%$. All other nodes are light gray (green) indicating

\footnotetext{
${ }^{6}$ In fully coloured online version of the paper the colours of the nodes range from red (strongest) to dark brown, light brown, dark green, and light-green (weakest). In the rest of the article, the colours of the nodes in the online version are given in parenthesis.
} 


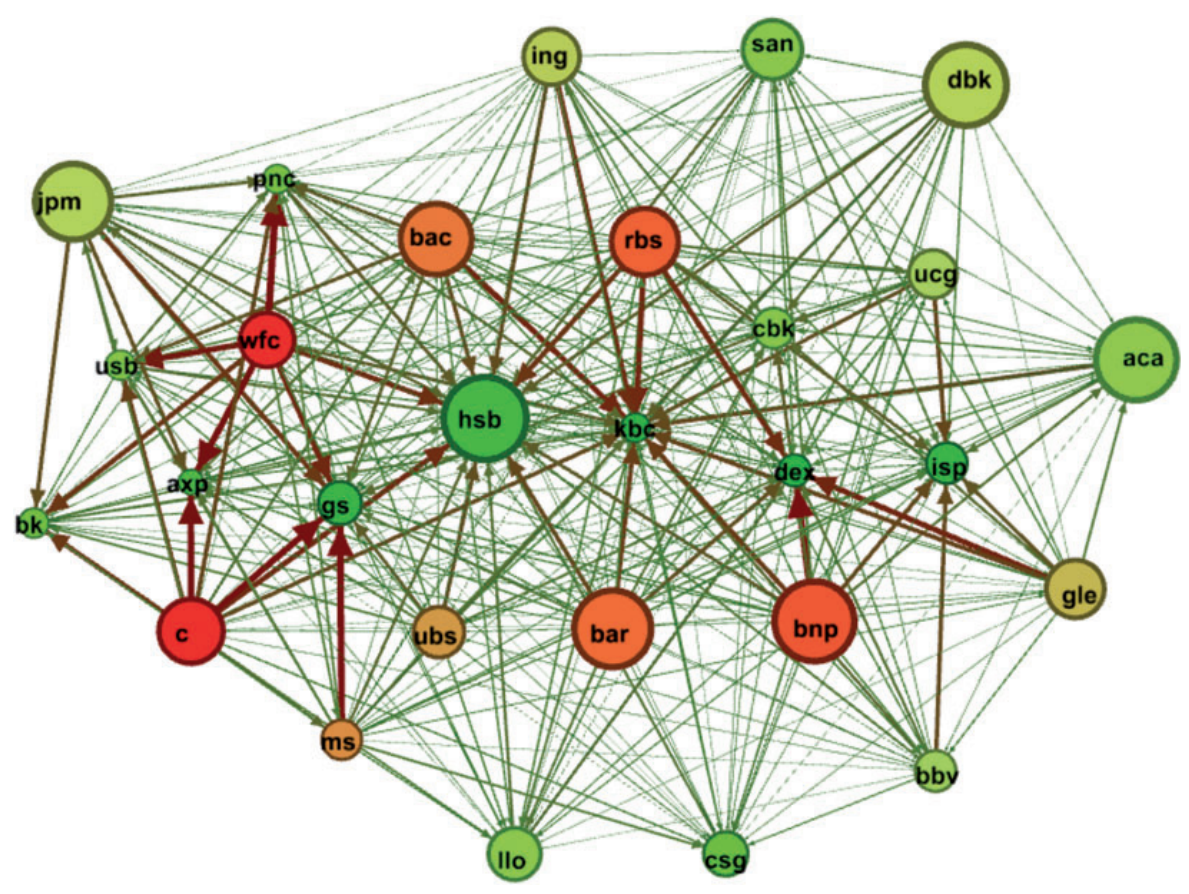

Figure 2 FI network across the Atlantic Based on pairwise directional "net" volatility connectedness over the full-sample, from January 2, 2004 to May 30, 2014.

that their net-connectedness measures are all negative, going as high as $28.5 \%$ in absolute value.

Figure 1 is quite informative about the total directional connectedness of each FI. However, it is not easy to decipher all pairwise connectedness among individual FIs from Figure 1 A table presenting all pairwise connectedness of the FIs in the full-sample would in principle be very useful. However, as there are 28 FIs in our full-sample analysis, it is not possible to present the results concisely. For that reason, we aggregate the connectedness measures at the national level, which allows us to diminish the size of the connectedness matrix to $9 \times 9$. The resulting full-sample cross-country connectedness table is presented in Table 3 This table is still informative about how volatility shocks to one or more FI stocks in a country spread to FI stocks in other countries. The diagonal elements (own connectedness) tend to be the highest individual elements of the table. Obviously, the diagonal elements are higher than non-diagonal ones, because they capture not only the ownconnectedness of each FI, but also connectedness of FIs within the same country. For example, the diagonal element for the United States, $689 \%$, measures both the own-connectedness of each American FI as well as its connectedness with other American FIs.

With the exception of the United States, total directional connectedness ("from others" or "to others") tends to be higher than the corresponding 
Table 3 Full-sample volatility connectedness table

\begin{tabular}{lrrrrrrrrrr}
\hline & BEL & GER & FRA & ITA & NLD & SPA & UK & SWI & USA & FROM \\
\hline Belgium (2) & 69.9 & 12.5 & 24.7 & 14.1 & 7.2 & 13.4 & 25.6 & 8.0 & 24.7 & 130.1 \\
Germany (2) & 9.2 & 45.8 & 27.5 & 16.0 & 9.5 & 14.9 & 27.2 & 15.9 & 34.1 & 154.2 \\
France (3) & 14.3 & 24.3 & 82.0 & 26.6 & 13.9 & 28.4 & 40.5 & 22.2 & 47.8 & 218.0 \\
Italy (2) & 11.4 & 15.8 & 31.7 & 51.8 & 8.3 & 21.2 & 25.7 & 11.5 & 22.5 & 148.2 \\
Netherlands (1) & 4.5 & 8.6 & 14.1 & 7.8 & 15.2 & 8.7 & 15.1 & 7.6 & 18.3 & 84.8 \\
Spain (2) & 9.9 & 14.6 & 31.9 & 19.2 & 9.0 & 53.2 & 24.2 & 12.2 & 25.8 & 146.8 \\
UK (4) & 15.2 & 26.1 & 42.0 & 22.1 & 15.4 & 25.0 & 125.0 & 29.4 & 99.8 & 275.0 \\
Switzerland (2) & 5.1 & 15.9 & 22.7 & 11.0 & 8.1 & 13.5 & 26.9 & 44.5 & 52.2 & 155.5 \\
United States (10) & 12.1 & 38.1 & 48.4 & 20.3 & 19.4 & 24.2 & 93.2 & 55.3 & 689.1 & 310.9 \\
TO & 81.7 & 155.8 & 243.1 & 137.0 & 90.9 & 149.3 & 278.3 & 162.1 & 325.2 & \\
FROM & 130.1 & 154.2 & 218.0 & 148.2 & 84.8 & 146.8 & 275.0 & 155.5 & 310.9 & \\
NET & -48.4 & 1.6 & 25.1 & -11.1 & 6.1 & 2.5 & 3.3 & 6.6 & 14.2 & $\mathbf{8 1 . 7}$ \\
\hline
\end{tabular}

Notes: The sample is January 2, 2004 through May 30, 2014, with 2685 daily observations. The $i j$-th entry of the upper-left $9 \times 9$ country submatrix gives the $i j$-th pairwise directional connectedness; that is, the percent of 12-day-ahead forecast error variance of all FIs located in country $i$ due to shocks from FIs located in country $j$. The last column (FROM) is equal to the row sum excluding the diagonal elements, and gives the total directional connectedness from all others to country $i$. The TO row at the bottom is equal to the column sum excluding the diagonal elements, and gives the total directional connectedness from country $j$ to others. The last row (NET) is equal to the difference between the "to" and "from" total directional connectedness. The bottom-right element (in boldface) is total connectedness (mean from-connectedness, or equivalently, mean to-connectedness) among 28 FIs. Finally, the number in parenthesis next to each country name indicates the number of FIs included in the analysis from the respective country.

own-connectedness. Total connectedness across all FIs (not across countries) obtained from the average of the "from others" column (or, for that matter, the average of the "to others" row) is a very high $81.7 \%$.

Let us now focus on the cross-country directional connectedness measures, namely, the off-diagonal elements of the $9 \times 9$ matrix, $\left(C_{i \leftarrow j}(H), i \neq j\right)$. The highest pairwise connectedness measure observed is from the United States to the UK $\left(C_{U K \leftarrow U . S .}(H)=99.8 \%\right)$. In return, the pairwise connectedness from the UK to United States $\left(C_{U . S .} \leftarrow U K(H)=93.2 \%\right)$ is ranked second. The difference between the two pairwise directional connectedness measures implies that the net pairwise connectedness from the U.S. to the UK FIs was not too small: $C_{U . S ., U K}(H)=6.6 \%$.

One factor behind the high pairwise directional connectedness between the U.S. and the UK is the high number of FIs from the two countries included in the analysis. Yet, as we have seen in Figure1 this cannot be the only reason. All UK FIs are located closer to the U.S., indicating that among the European FIs they are the ones that are most connected with the U.S. FIs. Furthermore, the connectedness from the U.S. to France (represented by three FIs in the analysis), 47.8\%, and from France to the U.S. $48.4 \%$, are approximately half of the respective pairwise connectedness measures between the U.S. and the UK.

High pairwise connectedness measures between the two countries therefore highlight the strong ties between the two countries' financial sectors. The high 
pairwise connectedness between the two countries could also be due to the fact that both countries are home to two most important centers in the global financial system. An increase in the volatility of FI stocks in one of the global financial centers has more important implications for the FIs in the other global financial center compared to FIs in other countries. Another important pair of countries is the United States and Switzerland. The connectedness from Switzerland to the United States, $55.3 \%$, and the connectedness from the United States to Switzerland, 52.2\%, both exceed the pairwise directional connectedness between the United States and France, even though Switzerland is represented by two FIs, UBS and Credit Suisse, in the analysis.

The row sum of the pairwise connectedness measures results in the total directional connectedness from others to each of the eight countries. In other words, the "FROM" column measures the share of volatility shocks received from FI stocks in other countries in the total variance of the forecast error for all FI stocks in each country. By definition, it is equal to the number of FIs times 100\% minus the own share of the total forecast error variance. As the own-effects (diagonal elements of the matrix) range between $15.2 \%$ and $689.1 \%$, the total directional "from" connectedness ranges between $84.8 \%$ and $310.9 \%$.

Similarly, the column sum of all pairwise connectedness measures results in the total directional connectedness to others of the corresponding country's major FIs. As each stock's contribution to others' forecast error variances is not constrained to add up to $100 \%$, entries in the "TO" row can exceed $100 \%$ times the number of major FI stocks from the country included in the analysis. While the financial stocks are largely similar in terms of receiving volatility shocks from others, they are highly differentiated as transmitters of volatility shocks to others.

For some of the nine countries, the "to-" and "from-connectedness" measures are not too far apart. For example, in the case of German FIs, the to-connectedness is only $1.6 \%$ higher than their from-connectedness. The net-connectedness of Germany is therefore quite small. In the case of Spain and Italy, the net-connectedness measures are $2.5 \%$ and $-11.2 \%$, respectively. While the two countries experienced serious problems in terms of the sustainability of their respective sovereign debts, over the full sample Italy's banking system turns out to be a net receiver of volatility shocks, whereas Spain is a net transmitter of volatility shocks. The difference is mostly due to the problems faced by their respective banking systems. While Spain suffered substantially from the losses of their regional FIs, Italian FIs did not have much trouble in terms of solvency. Even though those problematic Spanish FIs are not included in our analysis, their problems impacted the whole Spanish banking system including the two largest Spanish FIs included in our analysis.

Belgium has a negative net-connectedness, $-48.4 \%$, indicating that it is a netrecipient of volatility shocks from others. It is the highest "net" total connectedness figure in absolute value. It is so because its FIs, KBC and especially Dexia, suffered during the European debt and banking crisis and were taken to the government custody. Once that decision was made the stocks of these FIs were not subject to any new volatility shocks and therefore when we look at the full sample they do not turn out to have a significant impact on the U.S. and European banking systems. 
Among the banking systems that have positive "net" total connectedness, France has the highest value $(25.1 \%)$, followed by the United States $(14.2 \%)$, Switzerland (6.6\%) Netherlands, (6.1\%) and the UK (3.3\%). Three French FIs, BNP Paribas, Societe Generale, and Credit Agricole, generate significantly higher "net" total volatility connectedness compared to ten American FIs and four British FIs. One can try to explain this fact by referring to the share of sovereign debt stocks of Greece, Italy, and Spain held by the French FIs in their portfolio. There is definitely some truth to this. However, it is too early to reach this conclusion because there has been significant variation in the volatility of FI stocks throughout the 2004-2014 sample. Therefore, one has to wait for a detailed analysis of the dynamic measures of directional connectedness in order to reach a conclusion about the exposition of FIs to sovereign debt stocks that created serious trouble for the region's FIs.

Finally, with a value of $81.7 \%$, the total connectedness among twenty-eight FI stocks is higher than the total connectedness measures obtained in other settings, such as the connectedness among different asset classes, or among international stock markets (see Diebold and Yilmaz 2015). Given the large number of stocks included in the analysis, there is a high degree of connectedness for the full sample. As we will see later in analyzing the dynamic behavior of the total connectedness, there is always a high degree of connectedness even during tranquil times. There is another reason for the total connectedness for a set of financial stocks to be higher than for a set of major national stock markets around the world or for a set of asset classes in a country. As the institutions included in the analysis are all operating in the finance industry, albeit in different countries, both industry-wide and macroeconomic shocks affect each one of these stocks one way or the other. As some of these institutions and their stocks are more vulnerable to external and/or industry-wide shocks than others, they are likely to be transmitting these shocks to other financial stocks, generating a higher degree of connectedness to others. Obviously, to the extent that they have important implications for the rest of the industry, idiosyncratic volatility shocks are also transmitted to other FI stocks. For that reason, compared to a similar number of stocks from different industries, the connectedness for a group of stocks in the finance industry is likely to be higher. It is also likely to be higher compared to the connectedness for a group of global markets, as these markets are not subject to common shocks as frequently as the stocks from the finance industry 7

\section{DYNAMIC (ROLLING-SAMPLE, CONDITIONAL) ANALYSIS}

The full-sample connectedness analysis provides a good characterization of "unconditional" aspects of the connectedness measures. However, it does not help us understand the connectedness dynamics. The appeal of the connectedness methodology lies with its use as a measure of how quickly return or volatility

${ }^{7}$ We have in mind a comparison with the total connectedness indexes reported in Diebold and Yilmaz 2009 and Diebold and Yilmaz 2012. 
shocks spread across countries as well as within a country. This section presents the dynamic connectedness analysis which relies on rolling estimation windows.

Some of the major FIs that were part of the U.S. financial system until 2008 went either bankrupt or taken over by another institution or by the government during the U.S. financial crisis. Although we cannot include them in the fullsample analysis, we include them in the dynamic connectedness analysis for sample windows up to their respective demise. For sample windows from the beginning to May 30, 2008, there were seventeen U.S. FIs (making a total of thirty-five FIs) in the sample, including AIG, Fannie Mae (FNM), Freddie Mac (FRE), Merrill Lynch (MER), Wachovia Bank (WB), Lehman Brothers (LEH), and Bear Stearns (BSC). Bear Stearns was taken over by J.P. Morgan and its stock ceased to be traded on May 30, 2008. On September 15, 2008 Lehman Brothers went bankrupt and dropped out of the stock market, and our sample, on September 17, 2008.

We dropped the other five stocks (Merrill Lynch, Wachovia Bank, Fannie Mae, Freddie Mac, and AIG) from our sample as of the end of 2008, as either they were taken over by other companies (Merrill Lynch and Wachovia Bank) or they were taken to government conservatorship in September and October 2008 (Fannie Mae, Freddie Mac, and AIG). As a result, from May 30 to September 17, 2008, there are thirty-four, and from September 17 to December 31, 2008 there are thirty-three FIs in our sample. As we drop Merrill Lynch, Wachovia Bank, Fannie Mae, Freddie Mac, and AIG out of the sample on December 31,2008, we end up having twenty-eight FIs from January 2, 2009 to May 30, 2014.

\subsection{Total Connectedness}

Figure 3 plots total volatility connectedness over 200-day rolling-sample windows. We prefer to work with a 200-day rather than a 100-day window size because of the high number of variables included in the VAR analysis. From a bird's-eye perspective, the total connectedness plot in Figure 3 has some revealing patterns. After staying at the $70-75 \%$ band from 2004 through the first 4 months of 2006, the total connectedness index jumped from $72 \%$ to $76 \%$ in May 2006. Afterwards it increased gradually to reach $80 \%$ by September. The jump in May 2006 was a reaction to the Federal Open Market Committee's (FOMC) decision to increase the federal funds rate target in its meeting by 25 basis points as well as the announcement that there was room for another increase in its June meeting. The Fed's decision led to the unraveling of carry trade positions of many developed country investors in emerging market assets. Apparently, this led to a sell off in financial sector equities and an increase in volatility connectedness across the European and American FI stocks.

Putting the 2006 episode aside, one can discern three major cycles in the total connectedness plot. The first one lasted longer than the others. It started in June 2007 and followed the stages of the global financial crisis, all the way to mid-2009. The initial tremors of the subprime mortgage crisis were first felt at the end of February 


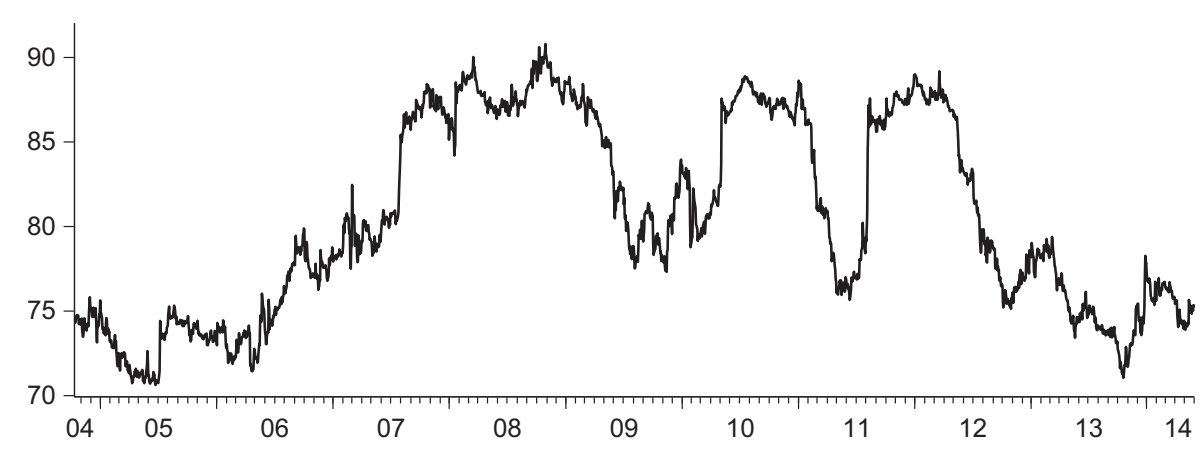

Figure 3 Dynamic total volatility connectedness with 200-day rolling-sample window. The predictive horizon for the underlying variance decomposition is 12 days.

2007. In a few days time, the index increased by five percentage points, but this was a temporary increase. Once the initial tremors of the subprime crisis led the way to the liquidity crisis in the summer of 2007, the total volatility connectedness index increased from $80.9 \%$ on July 25 to $85.4 \%$ on August 1, to $86.8 \%$ in mid-August and $88.5 \%$ on October 22.

As the initial tensions seemed to be eased, the index declined to $84 \%$ by midJanuary 2008. In the meantime, as the financial statements of the major U.S. FIs were announced everyone including the Federal Reserve had become more and more aware of the serious trouble facing the U.S. and the European FIs. As an acknowledgement of the troubles facing the financial sector, in an unscheduled meeting on January 22, 2008, one week before its regularly scheduled meeting, the FOMC lowered the policy rate by 75 basis points to $3.5 \%$. It was the first time that the Fed has implemented such a large cut in a single move. The index jumped from $84.8 \%$ on January 21 to $88.5 \%$ on January 22 . The FOMC cut the rate by another 50 basis points on its scheduled meeting on January 30. ECB and other major central FIs followed suit.

In March 2008 Bear Stearns moved to the center stage. Amid widespread rumors of an eventual bankruptcy, its stock price declined rapidly in mid-March, increasing the volatility connectedness to $90 \%$. On March 17, 2008, J.P. Morgan acquired Bear Stearns with financial assistance from the Fed. Following the Bear Stearns operation markets calmed down until the end of the summer. Then came the bankruptcy of Lehman Brothers on September 15, 2008, which immediately led to the "globalization" of the financial crisis. From a low of $87 \%$ in late August, the connectedness index increased in several steps to reach $91 \%$, the maximum ever, by mid-October.

Before the second major cycle the connectedness index went through two smaller cycles; one from mid-August to mid-November, the other from midNovember to the end of February 2009. The first one was due to the problems in the British banking sector. The index went up by 3.5 percentage points from 
mid-August to mid-September and came down. The second smaller cycle was an outcome of the revelations about the Greek fiscal deficit and debt stock. As the new Greek government revealed that the government budget deficit and the debt stock was actually much higher than announced by the previous government, it became clear that the losses of the European FIs holding the Greek debt would mount to billions of euros. Markets reacted and the volatility connectedness index moved up by 7 percentage points from mid-November to the end of December.

The second major cycle resulted from the inaction among the European policymakers against the Greek sovereign debt crisis of late-2009 and early-2010. For more than five months, in part because of the German elections in early May, European institutions could not come up with a workable solution to the crisis. In the meantime, the index started to climb again from $79 \%$ in mid-February to $82.5 \%$ at the end of April, before jumping up in the first week of May 2010 by another 5 percentage points to reach $87.6 \%$, days before the meeting of the EU leaders. As the meeting produced only a halfhearted solution, the index continued to climb in the next two months to reach $89 \%$ in mid-July. The connectedness index stayed high, between $86 \%$ and $89 \%$, until January 2011 before dropping down to $76 \%$ by May 2011.

The index did not stay low for too long, thanks to the increased worries about the sovereign debt and banking problems in Italy and Spain, two EU members with sizable economies compared to the members that had problems before. As the pressure on the two countries increased, the index went up gradually to reach $80 \%$ by late-July, before experiencing a jump to $87.6 \%$ in the first week of August. The problems of the European FIs continued through the last quarter of 2011, until Mario Draghi, the new President of the European Central Bank, announced the long-term refinancing operation (LTRO) plan to provide 1 trillion euros liquidity to Eurozone FIs in two installments. The last cycle in the connectedness index finally came to an end in the summer of 2012, as the data for the period are left out of the sample window and Mario Draghi in August declared that "ECB was ready to do whatever it takes to preserve the single currency." As of the end of September 2012, the total volatility connectedness across the 28 FIs in Europe and the United States stood at $75 \%$.

Toward the end of 2012, the heated political debate about the U.S. fiscal policy flared up again. While Republicans proposed spending cuts to control the budget deficit, Democrats wanted to increase taxes. As the two sides could not find a compromise solution, the automatic spending cuts were expected to take place by the year's turn. The so-called "fiscal cliff" unnerved the markets. In this atmosphere, the connectedness index increased gradually by four percentage points. However, a last-minute deal was struck to provide a temporary solution before the end of the year, and the volatility in the stock market did not necessarily go up any further. The index stayed around 79\% until March 2013, after which it started coming down again. Ben Bernanke's May 22 warnings about the eventual stopping of QE policies in late 2013 and/or early 2014 led to capital outflows from many emerging market economies in late-May and June. However, the impact of this announcement on the 


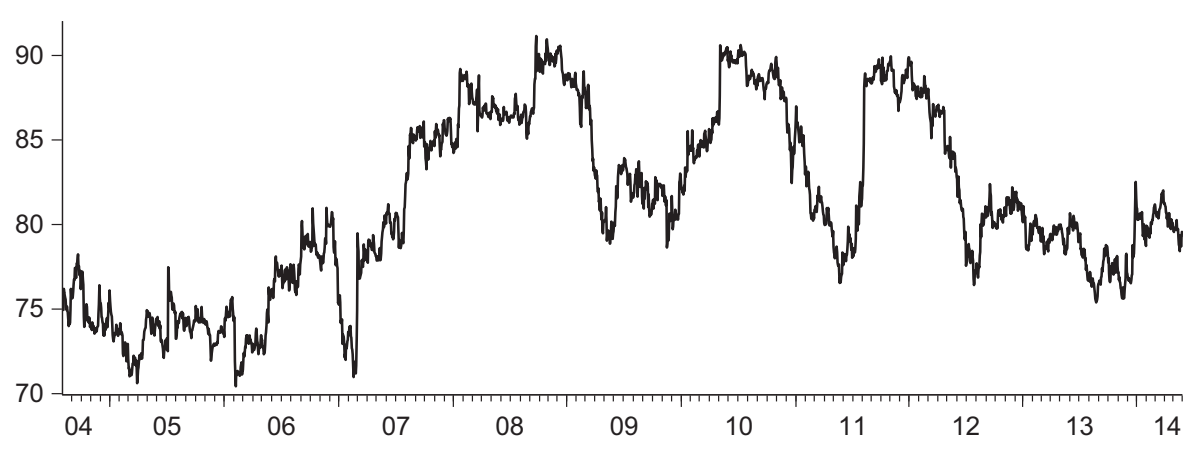

Figure 4 Rolling total volatility connectedness with 150-day rolling-sample window. The predictive horizon for the underlying variance decomposition is 12 days.

U.S. and EU FIs' stock return volatility was quite limited, with a three percentage point increase.

The connectedness index increased toward the end of 2012 and the end of 2013 due to the problems of some of the FIs with the authorities. In 2012, some of the major global FIs were forced to pay billions of dollars in fines in several countries for fixing the Libor rates. In 2013, it was BNP Paribas and Credit Suisse stocks that suffered mostly 8 In both cases, the impact on the connectedness index was temporary and no more than several percentage points.

As of the end of the sample, May 30 2014, the connectedness index is $75.3 \%$, just one percentage point higher than its value at the beginning of the sample. The index shows that the markets are calmer as of the end of May 2014 compared to the stormy period of 2007-2011.

So far we have relied on the 200-day rolling sample window estimation to obtain the connectedness index. However, as emphasized before, the shape of the total connectedness plot in Figure 3 is sensitive to the sample window size. We now reduce the window size to 150 days and plot the connectedness index in Figure 4 Even though the 150-day volatility connectedness plot Figure 4 is based on only the data for twenty-eight FIs that are included in the analysis from the beginning to the end of the sample, it is very similar to Figure 3 The index varies between $70 \%$ and $91 \%$. All three major cycles are discernable. Perhaps it includes further information in that the impact of the Fed's decision in May 2006 is clearly visible in Figure 4 Furthermore, the impact of the first tremors of the subprime crisis on the index is more visible when the 150-day window is used. The index jumps by 7 percentage points in late February to early March 2007. Other major developments in the U.S. financial crisis are also well captured by the connectedness index based on 150-day sample window. Furthermore, the other two major cycles in the index

\footnotetext{
${ }^{8}$ In the end, BNP Paribas and Credit Suisse settled with the U.S. government for $\$ 3.5$ and $\$ 2$ billion in May 2014. The FIs also faced criminal charges over tax evasion (Credit Suisse), and business with Iran and Sudan against U.S. sanctions.
} 
are also consistent with the ones obtained with a 200-day sample window. Finally, other minor cycles that started in mid-2009, mid-2012 and end-2013 are also visible in the 150-day connectedness plot.

\subsection{Total Directional Connectedness}

The dynamics of total connectedness provides one with a clear understanding of the financial market developments influencing the volatility connectedness across major U.S. and EU financial stocks. Keeping this analysis in the back of one's mind, it is now possible to focus on the dynamics of directional connectedness of the European and American FIs over time.

We conduct the dynamic analysis of the total directional connectedness in two steps. First, we group the FIs on each side of the Atlantic and analyze the volatility connectedness of the FIs on the American side with the ones on the European side. In the second step, we analyze the total volatility connectedness of some of the individual FIs vis-a-vis others.

3.2.1 Connectedness across the Atlantic. Figure 5 presents plots of total directional connectedness of FIs on both sides of the Atlantic. The upper panels (a) and (b) present the plots of volatility connectedness originating from the United States and Europe, respectively. The lower panel, on the other hand, brings together the directional connectedness from the United States to Europe and from Europe to the United States that appeared as dotted lines in the upper panels.

Let us start with the lower panel. There are three important observations one can make. First of all, the total directional connectedness across the Atlantic was rather low to begin with: the connectedness across the Atlantic fluctuated between $8 \%$ and 15\% before the 2007 subprime crisis. The Fed's decisions in May-June 2006 to increase its policy rate led the connectedness from the European to the U.S. FIs to increase gradually and reach $15 \%$ by early 2007 .

During the subprime crisis, the connectedness of the U.S. to European FIs increased in three steps. First, at the end of February 2007, the connectedness from the U.S. to European FIs jumped up by more than 5 percentage points. Second, during the liquidity crisis of late-July, early-August days, the connectedness from the U.S. to European FIs jumped by another 8 points to reach $19 \%$. Third, after a brief drop the connectedness from the U.S. to European FIs increased by another 7 points in October 2007 to reach $22.5 \%$ following the announcements by Citibank and other major FIs, disclosing huge losses incurred from their investments in mortgage based securities (MBSs). After reaching the peak in December 2007, the connectedness of the U.S. to European FIs declined temporarily, to increase again in the second-half of January 2008.

Interestingly, the volatility connectedness from the U.S. to European FIs increased by a total of 13 percentage points over the period from February 2007 to the first quarter of 2008. Over the same period, there was no significant increase 
(a)

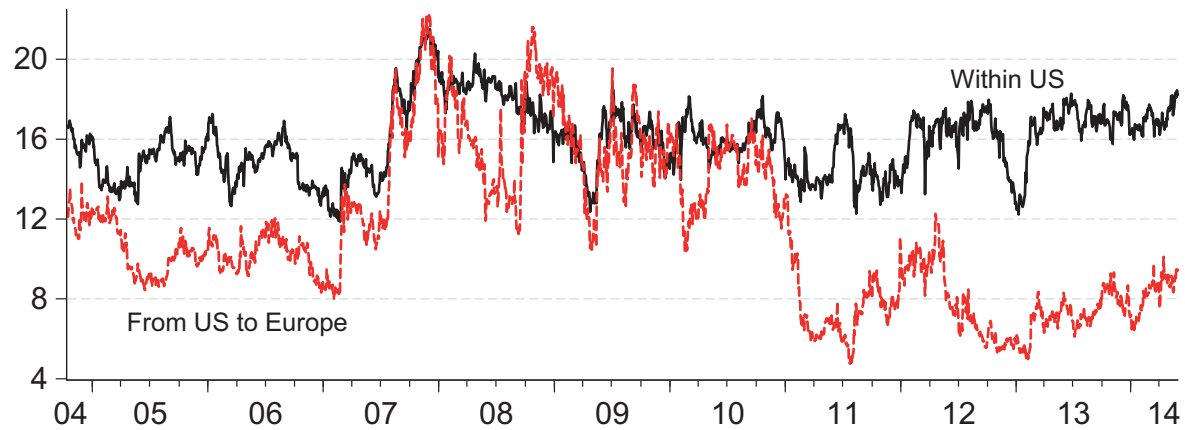

(b)

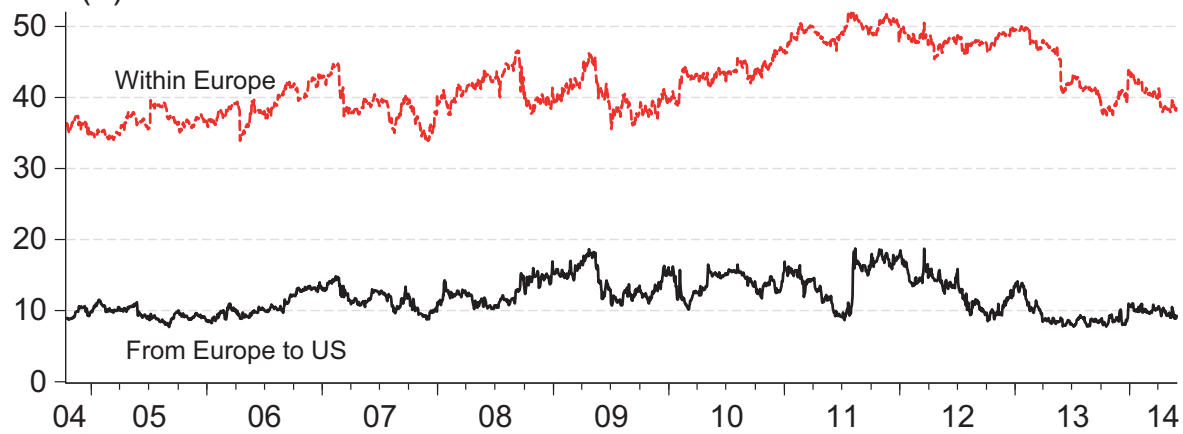

(c)

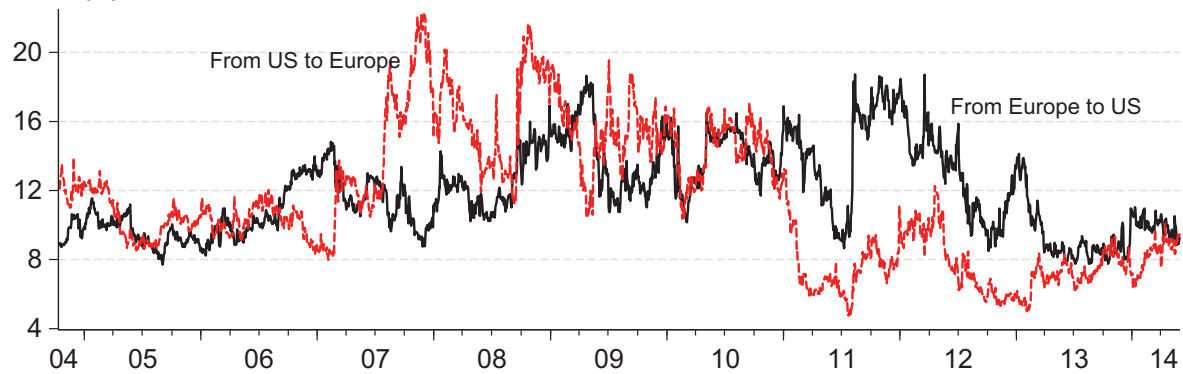

Figure 5 Directional volatility connectedness across the Atlantic (data for twenty-eight FIs). The rolling estimation window width is 200 days, and the predictive horizon for the underlying variance decomposition is 12 days.

in the connectedness of the European FIs to the U.S. FIs. It would therefore not be wrong to claim that in the build-up stages of the U.S. financial crisis volatility shocks that originated from the U.S. financial system were transferred across the Atlantic to European FIs. 
Following J.P. Morgan Chase's takeover of Bear Stearns in March 2008, the volatility connectedness from the U.S. FIs to their European counterparts declined gradually to $12 \%$ in the summer of 2008 . The difference between the two lines in Figure 55 narrowed down toward the end of the summer of 2008, to widen to 7$8 \%$ following the collapse of Lehman Brothers in mid-September. Even though, the "net" connectedness from the U.S. FIs to their European counterparts was positive at the end of 2008, it was smaller, around $4 \%$, compared to the earlier phases of the financial crisis. The high bidirectional volatility connectedness across the Atlantic following the Lehman's collapse was a clear sign of the U.S. financial crisis going global. Once the financial crisis turned into a global one, the troubles of the European FIs were magnified. While the connectedness from the European to the U.S. FIs was increasing in the first quarter of 2009, the connectedness from the U.S. FIs to their European counterparts was decreasing. As a result, in March-April 2009 European FIs became "net" transmitters of volatility to their U.S. counterparts.

In order to gauge the soundness of the U.S. FIs, the U.S. Federal Reserve conducted FI stress tests in early 2009. Before the Fed announced the stress test results in early May 2009, the directional connectedness of the U.S. FIs to the European FIs increased to reach closer to $20 \%$. While the test results were in general good for the whole U.S. financial system, the Fed asked some major FIs to raise additional capital to satisfy capital adequacy requirements. With small fluctuations, the connectedness of the U.S. FIs to the EU FIs stayed high within the $15-20 \%$ band throughout 2009.

After staying in the $10-15 \%$ band in the second and third quarters of 2009 , the European FIs' connectedness to their counterparts in the United States increased by more than five points in late 2009, following the news about sovereign debt problems in Greece. For the most part of 2010, the two directional indices moved together in the 10-16\% band, with almost zero "net" connectedness. As they both declined in the first few months of 2010, both directional indices increased again in the second quarter of 2010 following the EU's inability to put together a financial aid package that would help contain the Greek sovereign debt crisis. Six months after the public learned that the Greek sovereign debt stock was actually much higher than previously known, the EU finally announced a halfhearted financial rescue package to deal with the Greek sovereign debt crisis a few days after the German local elections in May 2010.

The within-connectedness of both the European and U.S. FIs (solid black lines in the upper panels of Figure 5 and b) fluctuated rather smoothly over the period from 2004 to the first half of 2006. However, following the Fed's decision to further increase the Fed funds rate target in May and June 2006, the within-connectedness of the European FIs gradually increased from $34 \%$ to reach $45 \%$ by early 2007 . As the window is rolled to include March 2007 in the sample, the within-connectedness of the European FIs dropped from $45 \%$ to $38 \%$. As the U.S. financial crisis intensified in 2008, the within-connectedness of the European FIs increased again to reach $46 \%$ in September 2008. After declining to $39 \%$ in late 2008, the within-connectedness of the European FIs gradually increased to $46 \%$ at the end of April 2009, following the 
problems in the British banking sector and the increased worries about the health of the European FIs.

After dropping down to $36 \%$ in the summer of 2009 , the within-connectedness of the European FIs started to climb up again in December 2009, following the news about the Greek sovereign debt troubles. It climbed steadily during 2010. As the EU scrambled to put together a workable financial aid package for Greece, the sovereign debt and banking troubles continued to simmer in other members of the EU. In two months time it was Portugal's turn. In July 2010, Moody's lowered Portugal's government bond ratings by two notches from AA2 to A1. News about the Portugal's worsening public finances continued through 2010 and the first quarter of 2011, culminating in an official $€ 78$ billion bailout by the EU. As a result, the upward move in the within connectedness of the European FIs lasted until February 2011, when it reached 50\%.

After Portugal, the focus shifted to the fiscal balances and banking sectors of two important members of the EU; namely, Italy and Spain. As the worries about the Spanish and Italian banking and sovereign debt problems intensified in June 2011, the within-connectedness of the EU FIs increased by another 5 percentage points at the beginning of August 2011, before declining gradually in the first quarter of 2012. Since 2012 the within-connectedness of the European FIs declined gradually to hit $37 \%$ in November 2013. Even though it increased again at the end of 2013, since then it declined to hit 38\% at the end of May 2014.

The dynamic behavior of the within-connectedness of the U.S. FIs is in many regards significantly different from the one observed among the European FIs. To start with, it is lower than the within-connectedness of the European FIs. This is due to the presence of a larger number of FIs in the European sample (18) compared to the U.S. sample (10) in the analysis. Furthermore, while the within-connectedness of the European FIs followed an upward trend with some corrections, the withinconnectedness of the U.S. FIs fluctuated between $12 \%$ and $18 \%$ for most of the sample period considered. It increased slightly to $23 \%$ in the final months of 2007. Interestingly, even though the crisis originated in the U.S. financial system, the within-connectedness of the U.S. FIs did not increase in the last quarter of 2008, during the heyday of the financial crisis. To the contrary, it continued its downward move with a small correction in the first half of 2009. It jumped by approximately 5 percentage points in late-April, early-May 2009, days before the announcement of the stress test results conducted on major U.S. FIs. From mid-2009 to mid-2011, the within-connectedness of the U.S. FIs fluctuated within the $16-20 \%$ band. For most of 2011, the within-connectedness of the U.S. FIs fluctuated around $16 \%$, with the exception of the May-August 2011 during which the worries about the disagreement between the Congress and the Obama administration on fiscal policy finally led to S\&P's decision to lower the U.S. federal government credit rating from AAA to AA+ on August 5, 2011.

In late 2010 and early 2011, the connectedness of the U.S. FIs to their counterparts in Europe declined rapidly to around 6\%, while the connectedness from Europe to the United States declined slowly down to $9 \%$ by mid-July. As the sovereign debt 
and banking crisis spread to Italy and Spain, the connectedness from the European FIs to the U.S. FIs jumped by 10 percentage points in late July and early August 2011, increasing the "net" connectedness of the European FIs to 11.5\%.

Even though the connectedness of the Eurpean FIs started to increase again in the last quarter of 2012, after the appointment of Mario Draghi as its President, there was a clear change in the policy stance of the European Central Bank (ECB). On December 12, 2011, the ECB announced a new facility to provide liquidity to the banking system with a longer maturity. Through the Long-Term Refinancing Operations (LTRO) ECB aimed at providing $€ 1$ trillion loans to the EU FIs with a maximum maturity of three years at an interest rate of $1.00 \%$. Immediately after the announcement of LTRO, fears about the European FIs subsided and the withinconnectedness of the European FIs and their connectedness to the U.S. FIs started to decline. Within a quarter both indices declined by about 6-7 percentage points. The connectedness of the European to the U.S. FIs continued its downward move until the end of 2012, with a total decline of 10 percentage points.

By the end of 2012, the connectedness of the U.S. FIs to the European FIs also declined to a level lower than the pre-crisis levels. However, the U.S. FI stocks are under the influence of the volatility that stems from the intense debate between the Obama Administration and the Republican Party about the fiscal policy stance. The rise in the directional connectedness of the U.S. FIs to the European FIs in the first half of 2012 and at the beginning of 2013 resulted from the uncertainty caused by the political disagreements between the two wings of the U.S. government. Finally, the small blip in the U.S. FIs' connectedness to the European FIs in late May and June 2013, was due to the Fed announcements that implied that the end of quantitative expansion policy of the U.S. Central Bank was getting nearer. The uncertainty caused by the elections in Italy increased the volatility connectedness of the Italian FIs in late 2012, and the directional connectedness from the EU FIs to the U.S. FIs.

All in all, as of the end of May 2014, the directional connectedness of the U.S. and the European FIs across the Atlantic declined to where they had been before the U.S. financial crisis and lower. The within-connectedness of the U.S. FIs was around $18 \%$, a couple percentage points above its value at the end of 2004 . The withinconnectedness of the European FIs was 39\%, again a couple of points above its value at the end of 2004. It is therefore possible to conclude that the global financial crisis and the ensuing tremors in the continental Europe led to the intensification of the within volatility connectedness of the European banking industry. As the volatility in the European banking industry subsided the within-connectedness of the European FIs went back to its intial levels.

3.2.2 Connectedness across countries. In this section, we analyze the connectedness of the major FIs in each country with their counterparts in other countries. In the previous section, we analyzed the volatility connectedness from the U.S. FIs to the EU FIs and from the EU FIs to the U.S. FIs. The difference between the two series is by definition the net-connectedness of the U.S. FIs vis-a-vis the 
other seven countries in the sample, all of which are members of the EU. As could be observed in the previous section, it was positive during the U.S. financial crisis, but moved into negative territory since 2010. These results are consistent with the essence of Figure 6 The net-connectedness of the U.S. FIs were the highest during the last 4 months of 2007 and early 2008, and the second quarter of 2009. It moved to negative territory in late 2010 and stayed negative since then.

Before moving to a detailed analysis of the "net-connectedness," let us briefly discuss the main characteristics of the "to-" and "from-connectedness" measures. For the majority of the countries in the sample from-connectedness plots are smoother. Actually, from-connectedness plots for six continental EU member countries resemble the total connectedness plot presented in Figure 3 The fromconnectedness plots for the United States differ from the from-connectedness plots for other countries, because American FIs actually generated the volatility connectedness to others during 2007 and 2008 until the collapse of Lehman Brothers. While the from-connectedness of other countries' FIs increased in 2007 and through 2008, American FIs' from-connectedness actually decreased in 2007 and fluctuated around 300 percentage points until the collapse of Lehman Brothers in mid-September 2008. The from-connectedness of the American FIs also jumped significantly (150 percentage points) following the collapse of Lehman Brothers. The from-connectedness of the British FIs jumped by 80 percentage points. Increases in other countries' from-connectedness was much less compared to the jumps experienced by the U.S. and the UK FIs' from-connectedness.

The dynamic behavior of the to-connectedness measures for each country are quite different from the dynamic behavior of the total connectedness measure. This is expected: when an idiosyncratic shock that originates in the banking system of a country spreads to others, this will only contribute to other countries' fromconnectedness with no effect on their to-connectedness. As the total connectedness measure is an average of the to-connectedness measures, its upward move will be limited compared to the to-connectedness of the country that was hit by the idiosyncratic shock. For example, the to-connectedness of the American FIs actually declined in 2011 and stayed low for much of the remaining period, while the toconnectedness of the continental European FIs increased further.

For the same reason, the to-connectedness of the countries in the sample differ from each other as well. While the to-connectedness of the German, French, Dutch, and British FIs increased following the Fed's decision to raise policy interest rates further in May and June 2006, the to-connectedness of the Italian, Spanish, Belgian, and American FIs did not increase much during that episode.

The to-connectedness of the U.S. FIs increased from $200 \%$ to $300 \%$ at the end of February 2007. It again increased during the liquidity crisis of August 2007, this time from $300 \%$ to $500 \%$. After a downward trend during much of 2008 , the toconnectedness of the American FIs jumped again in mid-September 2008 from $300 \%$ to $500 \%$. The to-connectedness of the U.S. FIs increased again in 2009 following the announcement of the stress test results in May 2009 and once more in spring and summer of 2010 along with the build up of the Greek crisis. 


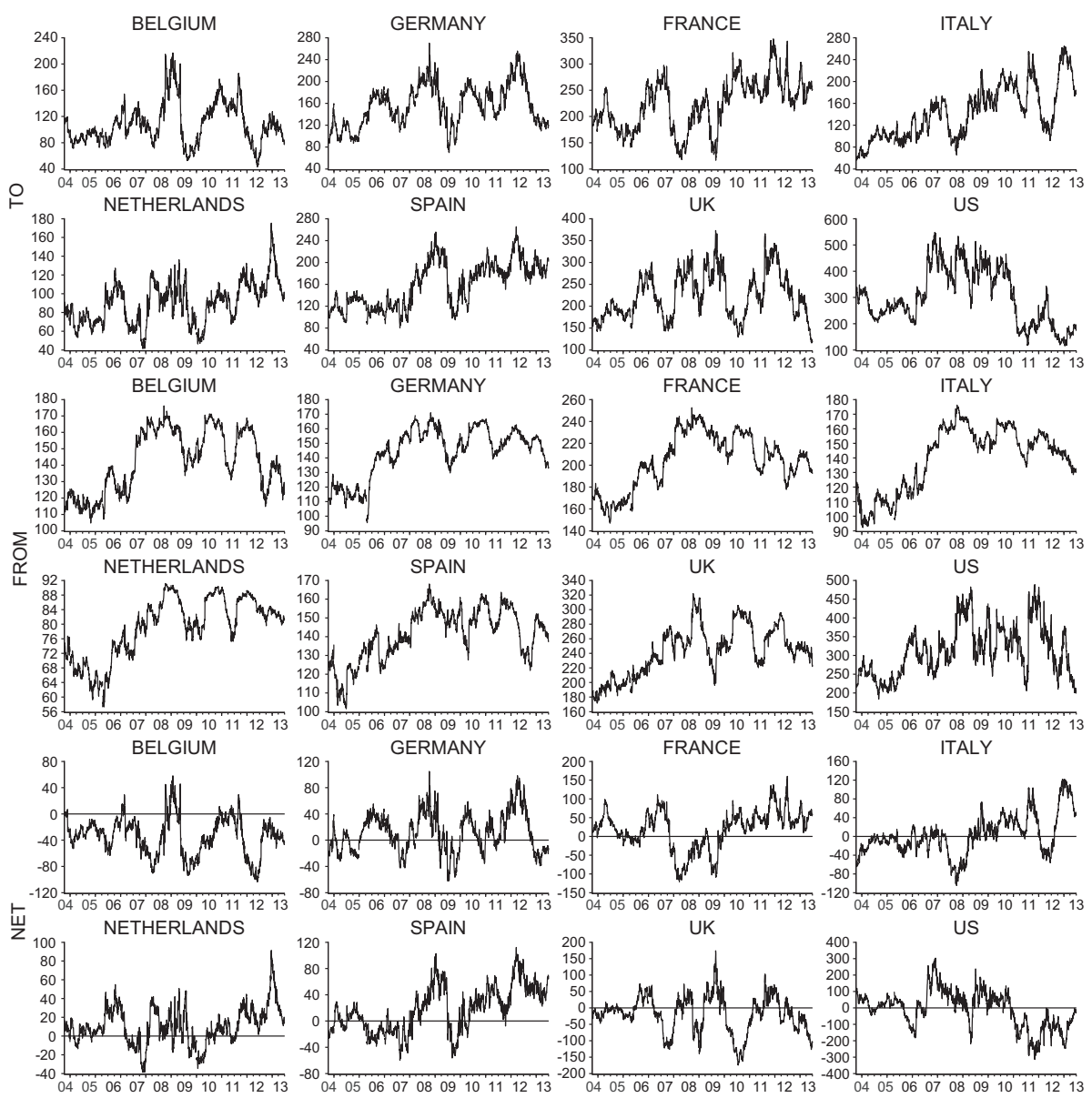

Figure 6 Directional volatility connectedness across countries.

High to- and positive net-connectedness of French FIs during the liquidity crisis of August 2007 show their troubles during this period. On August 9, 2007, BNP Paribas announced that it had frozen redemptions from three hedge funds, citing its inability to value structured products. German FIs also suffered badly from the crisis. IKB, a small German Bank was rescued through operations involving private and public FIs. As the crisis worsened, by the first quarter of 2008 almost all German FIs made losses from their investments in the United States. The value of assets they had to write down from their books during the crisis reached close to $\$ 25$ billion. Following the news about the write downs, net-connectedness of German FIs increased in the second and third quarter of 2008 and reached a maximum following the collapse of Lehman Brothers. Netherlands had high 
net-connectedness during 2006 and 2008-2009. UK FIs had significant losses in late 2008 and the first half of 2009 and their high to- and net-connectedness measures reveals the stress they were under. Belgian FIs were in trouble following the bankruptcy of Lehman Brothers, during which their to- and net-connectedness stayed high. Both Fortis and Dexia were in the brink of collapse. In September 2008, the French and Belgian governments supported Dexia with more than 6 billion euros. However, as the Greek crisis got worse the two governments decided to nationalize Dexia in October 2011. Fortis operations in Belgium, Netherlands and Luxembourg were broken up into three. While banking operations in Netherlands were nationalized banking operation in Belgium was sold to BNP Paribas.

In the summer of 2012, Italian FIs were hit by consecutive downgrades by the credit rating agencies Moody's and S\&P. First, Moody's downgraded twenty-six Italian FIs in May 15, 2012, followed by another round of credit rating downgrade for thirteen Italian FIs by Moody's on July 17 and further by another round of downgrade for fifteen Italian FIs on August 4 by S\&P. Following these downgrades both the to- and net-connectedness of the Italian FIs increased substantially in several months. The to-connectedness increased from around 110\% in May 2012 to $260 \%$ in late November 2012. The bad news for the Italian FIs were followed by the worries about the outcome of the Italian elections of February 28, 2013. As a result the to- and the net-connectedness of the Italian FIs did not start declining until March 2013.

The net-connectedness measures of Spain, Germany, France, Italy, and Netherlands were mostly positive since the beginning of 2010. The net-connectedness measures for Belgium, the UK and the United States, on the other hand, were mostly negative during the 2010-2013 period. The Belgium FIs already suffered big blows in late 2008 and early 2009, and were put on life support from the government. Afterwards, they were in a passive mode, which explains their negative net-connectedness for most of the 2010-2013 period.

During the faithful months of the summer of 2011, the sharpest increase in the net-connectedness was observed for the Italian, Dutch, French, and German FIs. Interestingly, after the global financial crisis Spanish FIs' net-connectedness increased only toward the end of 2010. This shows that in the summer of 2011, the markets were more worried about the sustainability of the Italian sovereign debt stock and the future of Italian FIs, rather than the Spanish FIs. The netconnectedness of Italy declined sharply in late 2011 and early 2012 following the ECB's announcement of LTRO in December 2011. However, there was not an immediate impact on the net-connectedness of the Spanish FIs. Instead, following the two rounds of LTRO the net-connectedness of the Spanish FIs started to increase in the first quarter of 2012. From around 10\% to $20 \%$ levels their netconnectedness reached to $100 \%$ level by mid-March 2012 . Their net-connectedness started to decline afterwards and fell as low as 40\% levels in late 2012 and for most of 2013. However, the signs from the U.S. Federal Reserve that they might eventually wind-down the quantitative easing program in late 2013 or early 2014 led to a major reversal in capital outflows. The Spanish FIs were 
affected as their net-connectedness increased from 31\% on May 20 to $68 \%$ by the end of June?

3.2.3 Connectedness at the institution level: U.S. Fls. As we have seen above, American FIs as a whole generated high levels of net volatility connectedness during the build up phase of the U.S. financial crisis that eventually led to the global financial crisis of 2008-2009. In the post global financial crisis era, however, the direction of volatility connectedness has been mostly from the EU towards the U.S. FIs. In the remainder of this section, we analyze the directional volatility connectedness of each of the U.S. and the EU FIs in order to understand how the developments in each individual FI led to high stock return volatility and volatility connectedness.

Let us start with Wells Fargo (WFC), the U.S. FI that generated the largest net volatility connectedness among all 28 FIs in the full-sample analysis presented in Figure 2 Had it not purchased Wachovia, one of the major U.S. FIs that suffered substantial losses during the crisis, Wells Fargo would have contributed much less to the volatility connectedness across the U.S. and European FIs. In the preWachovia acquisition period, the net volatility connectedness of WFC never rose above $30 \%$, and most of the time fluctuated around zero. During the heyday of the crisis, in the last quarter of 2008 the net-connectedness of WFC was briefly in the negative territory, indicating how it was affected from systemic risk generated by others. Despite the strength of its own financial position, Wells Fargo was affected badly from the balance sheet troubles of the FI it acquired. Before and after the announcements of the stress test results in May 2009, WFCs stock return volatility and volatility connectedness increased substantially. Stress test results revealed that WFC was expected to raise $\$ 13.7$ billion in additional capital. After Bank of America, this was the largest amount of capital the authorities required any U.S. FI to raise. As a result of these developments, WFCs net-connectedness increased substantially in the summer of 2009 to reach $60 \%$. However, the troubles of WFC did not last long as the FIs balance sheet excluding Wachovia was in good shape. The dynamic analysis of the volatility connectedness of Wells Fargo is very revealing in that it shows how misinformative could the full-sample analysis be about the state of the individual FIs.

Citigroup, on the other hand, had the third highest "net" volatility connectedness after Wells Fargo and Barclays. The fact that Citigroup had high net volatility connectedness at various instants during the crisis shows how troubled the FI was during the financial crisis. It created net positive volatility connectedness starting from October 2007 through the second quarter of 2008, as well as following the

\footnotetext{
${ }^{9}$ Being the largest FIs in the Spanish system, BBVA and Bank Santander, are included in the analysis to represent returns and volatility in the Spanish banking system. The fact that the Spanish banking system was in trouble, however, does not necessarily imply that the two Spanish FIs that are included in the sample were in trouble per se. Despite their strong balance sheets, their stocks came under great pressure along with the rest of the Spanish banking system.
} 

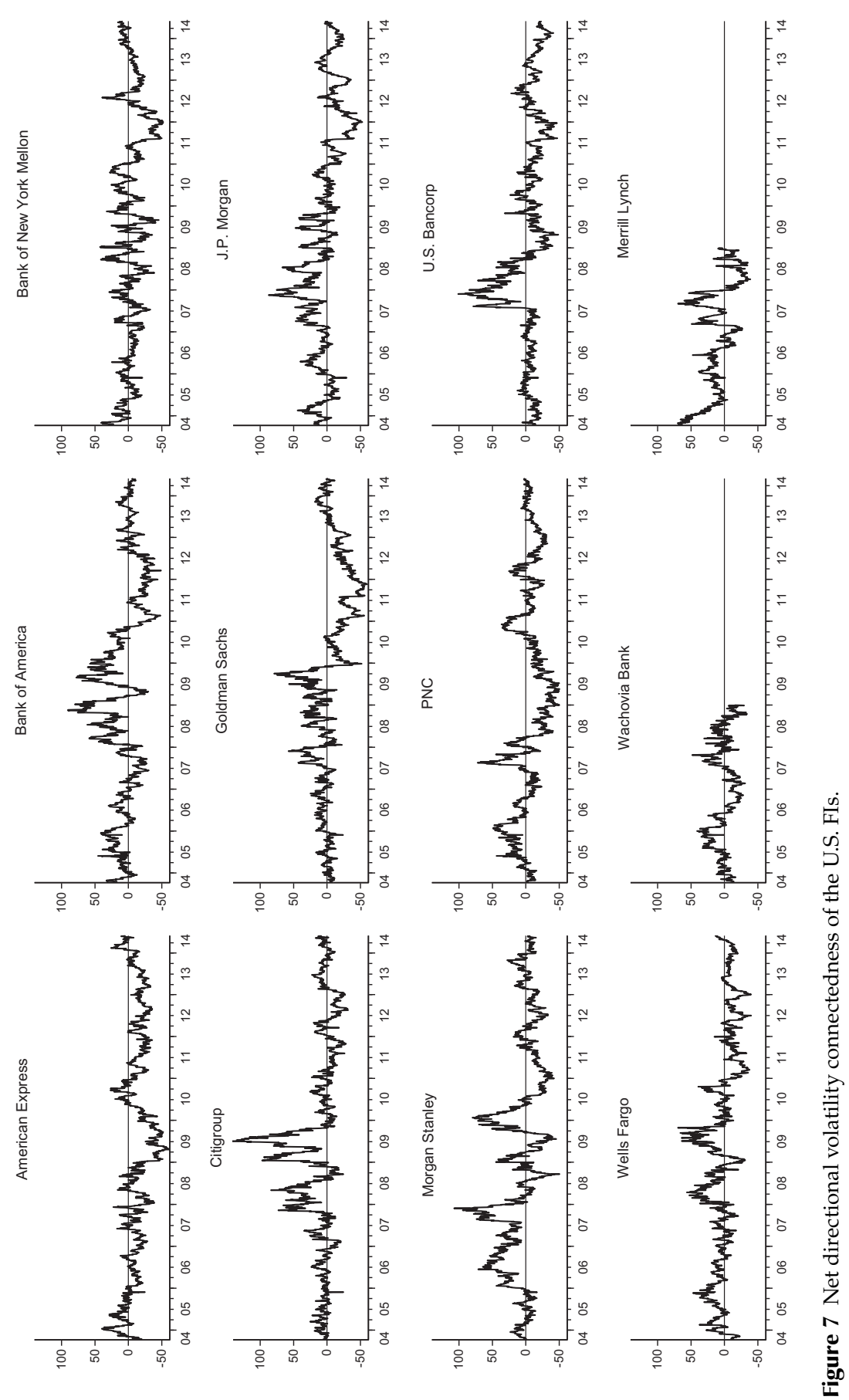
collapse of Lehman Brothers and in most of 2009. On October 1, 2007, Citigroup announced a $\$ 5.9$ billion write-down due to subprime losses. Such a big loss led to the resignation of its CEO, Chuck Prince, in a few weeks time. Citigroup's losses increased over time. As of March 2008, Citigroup accumulated a total of \$22.4 billion in write-downs and credit losses stemming from the collapse of the U.S. subprime mortgage market 10 From October 2007 onwards Citigroup's net volatility connectedness increased to 70\% in November, and 85\% in May 2008 (see Figure7.

The financial stocks came under pressure again in the week of November 16-21, 2008. Citigroup's balance sheet continued to worsen, making it a source of real worry for the market participants. Over the weekend of November 22-23, the government officials and Citigroup executives agreed on a plan to effectively bail out the FI. In addition to $\$ 25$ billion funds provided through TARP in October, the Treasury provided $\$ 20$ billion to Citigroup. Furthermore, the government effectively guaranteed potential losses on Citigroup's $\$ 335$ billion portfolio, in exchange for preferred shares and warrants. As a sign of continued pressure in the markets, in its December 16 meeting the FOMC further lowered the Federal funds rate between 75 and 100 basis points and allowed it to fluctuate between zero and $0.25 \%$.

As a result of these measures, Citi's "net" connectedness increased only slightly to reach $27 \%$ in November 2008. After this period, Citi's net volatility connectedness increased again to reach $100 \%$ in January 2009, as its net losses in the previous five quarters accumulated to reach $\$ 37$ billion by the end of 2008. On February 27, 2009, the U.S. federal government and the Citigroup agreed on a third bailout package which effectively converted $\$ 25$ billion in preferred shares into common shares, increasing the government stake to $34 \%$ of its market value. Following the third rescue package, the net volatility connectedness of the Citigroup stock declined to as low as 10\% in April 2009.

According to the stress test results, the Citigroup needed to raise $\$ 5.5$ billion in fresh capital to strengthen its balance sheet. Since it was an amount that could be raised from private investors without much difficulty, the announcement did not lead to an increase of the volatility of the Citigroup stock. However, several weeks after the announcement, the Federal Reserve and the U.S. Treasury started to exert pressure on Citigroup to revamp its board of directors by appointing new independent members. According to news reports, Federal Deposit Insurance Corporation (FDIC) was said to be pushing for the departure of the top management, including the CEO of the company. As a result, the Citigroup's net volatility connectedness started to increase in May 20 again and reached its highest level, 135\%, on July 7, 2009. As the February 27 deal between the government and the Citigroup was approved by other preferred shareholders and following the appointments of eight new independent members to the board of directors, the netconnectedness of the Citigroup stock started to decline and hit the zero line by the end of October 2009. From then on, the FIs net-connectedness never exceeded 25\%.

\footnotetext{
${ }^{10}$ See "Subprime Losses Reach $\$ 195$ Billion," March 14, 2008. http://www.bloomberg.com/apps/news? pid=newsarchive\&sid=axW.W8dqt1xA. Last accessed October 31, 2015.
} 
Bank of America was the other major U.S. FI that generated substantial net volatility connectedness to major U.S. and EU FIs. Similar to Wells Fargo, Bank of America itself did not directly get involved in the U.S. subprime mortgage market. However, its decisions to purchase Countrywide Financial, one of the leading mortgage generators, on January 112008 and Merrill Lynch in September 2008 exposed Bank of America directly to the risks associated with the U.S. subprime mortgage market. As a reflection of this fact, the net-connectedness of BAC increased to $56 \%$ by early-April and $62 \%$ by mid-July reaching the highest level of $90 \%$ following the bankruptcy of Lehman Brothers.

Merrill Lynch's investments in the MBS and ABCP continued to haunt BAC even after the U.S. financial system had left the worst behind. The announcement of the stress test results put Bank of America in the spotlight again. The stress tests showed that Bank of America had to raise $\$ 33.9$ billion in new capital. This was the largest amount to be raised by the U.S. FIs that were subjected to the test. The bulk of BAC's problems, including the negative stress test results, that led to higher volatility in the stock followed from its acquisition of Merrill Lynch in late 2008. The stock was under pressure from shareholder anger following the news about a total of $\$ 3.6$ billion bonuses being paid by Merrill Lynch management to their employees days before the closing of the acquisition by BAC. On May 16, 2009, regulators pressured Bank of America management to overhaul its board of directors. The pressure continued throughout the summer, which eventually led to the resignation of the CEO of the company, Ken Lewis, on October 5, 2009.

As a result of these developments, BAC stock went through a period of high volatility throughout the summer and its net volatility connectedness increased further to reach $78 \%$ by late-August 2009 . Even though the net volatility connectedness of BAC declined slightly to below $20 \%$ in late-October 2009 following Ken Lewis' resignation, it increased again to around $60 \%$ in the last two months of 2009 and first two months of 2010. Since the end of 2010, the "net" connectedness of the Bank of America mostly stayed in the negative territory.

J. P. Morgan Chase (JPM) experienced a period of sizable net volatility connectedness once the problems in the U.S. subprime mortgage market had started in 2007. However, its net-connectedness never increased above $60 \%$ during this period. Furthermore, its net volatility connectedness stayed high only for short periods of time. Being one of the largest U.S. FIs, it makes sense to see JPM to be one of the FIs that generated positive net-connectedness during the heyday of the U.S. financial crisis. A comparison of JPM's net-connectedness plot with those of the Citigroup and Bank of America shows that JPM contributed much less to the systemic risk than its main competitors during the U.S. financial crisis.

Aside from the top four U.S. FIs, other major FIs also experienced substantial increases in their net volatility connectedness during the U.S. financial crisis. Here we briefly discuss their connectedness plots. U.S. Bancorp experienced a substantial increase in its net-connectedness during the liquidity crisis of 2007 , reaching $79 \%$ in August and close to $100 \%$ in late November 2007. During this time period, its stock price declined from \$34.5 in May 2007 to around \$30 in July 2007. Its 
net-connectedness declined gradually in December 2007 and throughout 2008, but it was still around $40 \%$ just before the collapse of Lehman Brothers. After Lehman's collapse, the net-connectedness of U.S. Bancorp declined sharply to negative territory and fluctuated below or around zero. The fact that USB's netconnectedness was negative after Lehman's bankruptcy shows that it was affected by from the systemic risk generated by Lehman, AIG, and other more problematic U.S. and European FIs.

Morgan Stanley's stock was one of the more volatile stocks among the major U.S. FIs. Over the sample period, Morgan Stanley experienced five upticks in its net volatility connectedness. Its net volatility connectedness moved to positive territory in early 2006 and increased further to reach 70\% following the Federal Reserve's decision in May 2006 to increase the federal funds rate target further. There was another upward move in early 2007, following the collapse of several mortgage originators. It was one of the stocks that suffered the most during and after the liquidity crisis of 2007. During this episode, its net volatility connectedness increased to $80 \%$ by late-August and to $110 \%$ by late-November. Following Lehman's collapse, its "net" connectedness increased slightly to reach $45 \%$ by January 2009. Finally, it suffered the worst increase in the second half of 2009 and early 2010 as a result of its continuing losses in the second half of 2009. As a result, its netconnectedness reached $75 \%$ in the first few weeks of 2010 . The pressure on the stock dissipated since mid-2010, with its net-connectedness falling below zero.

Even though it is an investment bank, Goldman Sachs has been one of the less problematic FIs in the United States. Its net-connectedness increased during the liquidity crisis of 2007 to around $50 \%$ and in the period from May through September 2009 to reach $75 \%$. Both of these periods coincided with the sectorwide high connectedness episodes. Goldman Sachs had negative net volatility connectedness for most of the period since the end of 2009.

American Express had positive net-connectedness in late 2010, but even then its net-connectedness was at most $20 \%$. PNC had four episodes during which its net volatility connectedness reached to levels as high as $60 \%$. However, all of these episodes did not last very long. Bank of New York Mellon also had low net-connectedness for most of the 2004-2013 period. Its net-connectedness increased to $40 \%$ only in late 2008 following the collapse of Lehman Brothers. Its net-connectedness also increased during the summer of 2012, but only for a very brief period. This increase followed a court ruling against the FI for its trustee role for the mortgage backed securities sold by Countrywide Financial Corporation to four big pension funds in the Chicago Metropolitan Area.

Merrill Lynch and Wachovia were among the major U.S. FIs that had to be acquired by other FIs, Bank of America and Wells Fargo, respectively, in order to avoid the fate of Lehman Brothers 11 Actually, in the faithful weekend that determined the fate of Lehman Brothers, the two FIs were able to find suitors

\footnotetext{
${ }^{11} \overline{\text { We present their net total volatility connectedness in Figure } 7 \text { in order to use the space available in the }}$ graph.
} 
forced in part by authorities. From 2002 to 2004 Merrill Lynch suffered from lawsuits against the firm. It ended up paying millions of dollars to settle the allegations. In the case of their involvement in the Enron scandal several of its executives were jailed in 2004. As a result of these developments Merrill's stock was under pressure. Its "net" volatility connectedness stood at 70\% in October 2004 and gradually declined over time. Its "net" connectedness increased briefly in the summer of 2006 following the Fed's decision to tighten the monetary policy. Its connectedness increased to 50\% in March 2007 and to $90 \%$ in September 2007. Its "net" connectedness declined in 2008 and stayed low until the end of 2008 when its stock ceased to be traded.

Based on total assets in 2008, Wachovia was the fourth-largest bank holding company in the United States. However, its 2006 acquisition of Golden West Financial, a mortgage-originator savings and loan bank in the West Coast, became a real burden for the firm. It began to experience heavy losses in its loan portfolios due to the subprime mortgage crisis. It announced worse than expected $\$ 8.9$ billion in losses in the second quarter of 2008 with more to come later. Its net-connectedness increased to $50 \%$ following the liquidity crisis in September 2007. Throughout 2008 its net-connectedness stayed positive, but it was not very high. After talks with Citigroup that lasted for a while, Wachovia's board of directors accepted the acquisition offer by Wells Fargo in October 2008.

In Figure 8 we present net total directional volatility connectedness plots for Lehman Brothers, AIG, Fannie Mae, Freddie Mac, and Bear Stearns. Let us start with Bear Stearns. Bear Stearns's net-connectedness briefly increased to $18 \%$ in November 2006, but declined quickly. Then, as the first round of news about its hedge funds's bad subprime mortgage investments circulated its net-connectedness increased to $40 \%$ in May 2007. Its net-connectedness increased to 53\% during the liquidity crisis and declined afterwards. Then, from January 2008 on wards it started to gradually increase until March 17, when its net-connectedness shot up to $125 \%$. That same day, Bear Stearns was sold to J.P. Morgan in an operation organized by the New York Fed.

Lehman's net-connectedness increased very quickly during the liquidity crisis, reaching 51\%. Even though it declined afterwards, it fluctuated between 0 and $35 \%$ in late- 2007 and early-2008 and hit $40 \%$ on the day Bear Stearns was acquired by J.P. Morgan. Then in the summer of 2008, it gradually increased to reach $75 \%$ by mid-July. Even though it declined to $40 \%$ by late-August it quickly increased again and shot up to $83 \%$ one day after its bankruptcy decision was announced on September 15.

AIG's net total volatility connectedness was close to zero until the liquidity crisis. After the liquidity crisis it started to increase gradually to $45 \%$ by midDecember 2007. After a brief correction, it increased again in late-February 2008. This time it reached $60 \%$ and stayed high until early May. It declined again to increase gradually and quickly in early September and went up to reach $235 \%$ on September 19, 2008. Despite the fact that the authorities decided to lend $\$ 85$ billion to AIG immediately, it proved insufficient and AIG's problems continue to pressure 

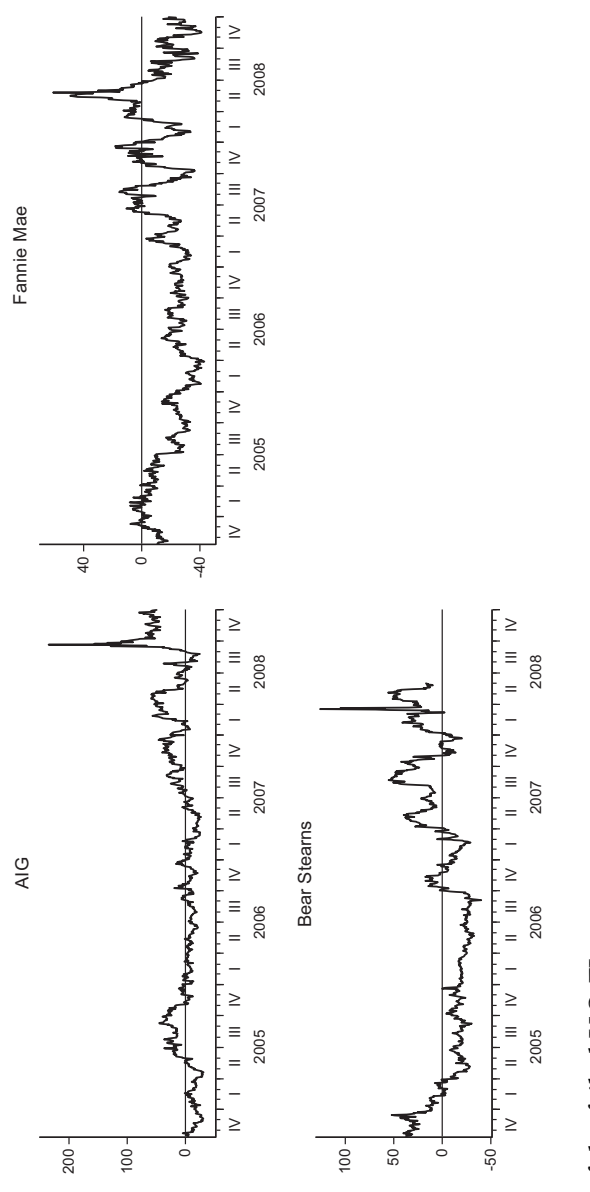

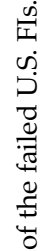

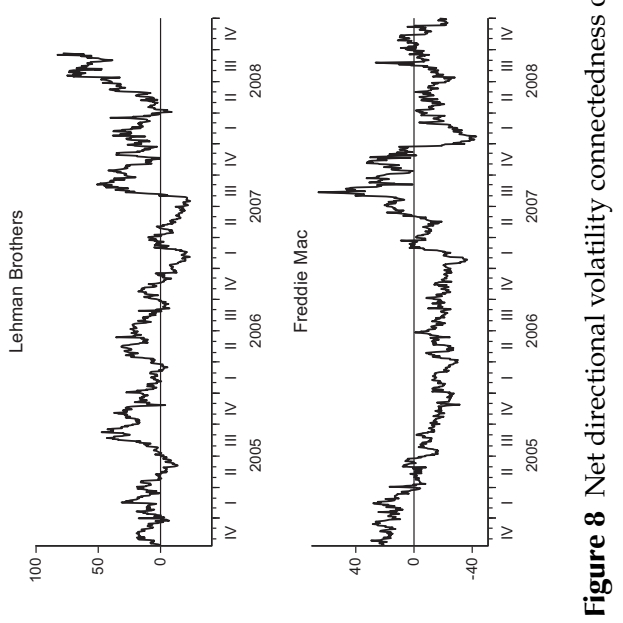


the markets. Its net-connectedness declined to $70 \%$ by mid-October and continued to stay above $50 \%$ until the end of the year.

Fannie Mae had high (61\%) net-connectedness briefly in late May 2008. Freddie Mac, on the other hand, had its high net-connectedness $(66 \%)$ during the liquidity crisis of 2007. In late August 2008, Freddie Mac's net-connectedness increased for a couple of days. Then in the first week of September U.S. government decided to take both FIs to government conservatorship. After this decision, neither of the two firms generated much connectedness to others.

3.2.4 Connectedness at the institution level: European Fls. As we have already discussed above, in the connectedness analysis each European country is represented by a few large FIs. We now move to the analysis of the net directional connectedness of each of the European FIs. We start the with the Swiss FIs. Both of them, but especially UBS played important roles in generating volatility connectedness to other FIs and therefore need special attention. During the last 7 years UBS' name has been on the news in many occasions, most of the time due to its scandals and/or difficulty in sustaining profitability.

UBS was one of the major players in generating the volatility connectedness to others during this period. Being one of the most conservative international FIs, UBS was the first FI to announce heavy losses from subprime investments of its hedge fund arm in the U.S., Dillon Read Capital Management. As a result, UBS had high net-connectedness in the early stages of the subprime crisis (60\%). In the end UBS decided to close Dillon Read on May 4, but the losses from the subprime investments continued to mount leading to the ousting of its CEO by its board of directors in July. The FIs total net-connectedness increased further to $81 \%$ in June 2007. Even though, the net-connectedness of UBS declined to $60 \%$ during the liquidity crisis, it was still high. UBS' net-connectedness increased again, to $88 \%$ in mid-January 2008 as the bad news about the balance sheets of major FIs started to circulate in the United States and Europe. UBS' net-connectedness declined afterwards; during Lehman's collapse UBS was on the receiving end, with negative net-connectedness. Following the fall back after Lehman's collapse, UBS received a $\$ 59.2$ billion bail out package from the Swiss government on October 16, 2008. Its net directional connectedness was negative until the first half of 2010.

In September 2011, UBS announced that it had lost $\$ 2$ billion as a result of unauthorized trading performed by one of its directors in equities trading desk in London. Its CEO and several top officials resigned in late September. Then came the unfolding of the Libor fixing scandal in several countries. In early December Japanese authorities announced that they found out that staff at UBS had attempted to influence Tibor, Tokyo interbank lending rate. During this period, UBS' netconnectedness increased to reach $80 \%$ by mid-December 2011 . Even though its connectedness declined slightly in early 2012 it increased again to reach close to $100 \%$ by May, when UBS announced that its profits had dropped by $54 \%$ due to accounting charges. In the end, UBS had to pay a fine of $\$ 1.5$ billion to the U.S. 
government for its involvement in the Libor fixing scandal. However, this latest development did not have much effect on its stock, because the markets had already priced it.

The other Swiss FI, Credit Suisse, did not have much difficulty during the U.S. financial crisis. It did not have as bad a balance sheet as UBS had, and hence did not need any financial support. In late-October 2009, EU regulators decided that EU-aided ING Bank should separate its banking and insurance operations. This decision led to a sell-off in European FI stocks. Being one of the rapidly rising stocks in the previous several weeks, Credit Suisse declined very quickly with corrections on the way. As a result, Credit Suisse's net volatility connectedness to others increased quickly to reach $77 \%$ by mid-November. Its net-connectedness fluctuated around $50 \%$ in the first-half of 2010. Even though Credit Suisse's netconnectedness declined to around 20-30\% levels in the second-half of 2010, it went up again in 2011 and especially toward the end of 2011. Its net-connectedness shot up from $-30 \%$ in late 2013 to reach $50 \%$ by mid-January following the news about the U.S. government investigation against Credit Suisse and several other Swiss FIs for aiding rich Americans to evade taxes. In the end, in May 2014 Credit Suisse agreed to pay a hefty fine of $\$ 2.6$ billion to settle the case.

Next we have a quick analysis of the Belgian FIs' net-connectedness. Dexia, which was actually a Belgian-French FI, experienced a jump in its netconnectedness briefly in at the beginning of March 2007. Then, following Lehman's bankruptcy in September 2008, both Dexia and KBC experienced an increase in their net-connectedness. The increase in Dexia's net-connectedness was smaller, even though Dexia was in worse shape than KBC. Immediately after the Lehman bankruptcy, at the end of September 2008 Belgian, French and Luxembourg government granted Dexia a bailout package of $€ 6.4$ billion. Once it received this amount, its net-connectedness declined from $50 \%$ to close to zero. Its netconnectedness was very low and even negative for a long time as it was kept afloat by government funds.

$\mathrm{KBC}$ also received bailout funds from the government, but it applied to the Belgian government toward the end of October 2008 and during the month of October its net-connectedness stayed high. However, $€ 3.5$ billion received from the government was not sufficient and $\mathrm{KBC}$ continued to have problems toward the end of the year. When it applied for additional funds, the Federal government stayed away and this time the regional Flemish government provided $€ 2$ billion. KBC's net-connectedness declined only after this deal.

In the second quarter of 2011, Dexia posted a loss of $€ 4$ billion due to losses in the Greek sovereign bond market. As a result, Dexia's net-connectedness briefly rose to $40 \%$ during the summer 2011 phase of the European crisis, but subsided down quite quickly again thanks to further funds received from the Belgian government.

Deutsche Bank is the dominant FI in the German banking system. Since 2004 Deutsche Bank's net-connectedness went through four episodes of important increases. Following the Fed's decision to increase the policy rate further Deutsche Bank's net-connectedness increased to $40 \%$. As the news about the merger of three 

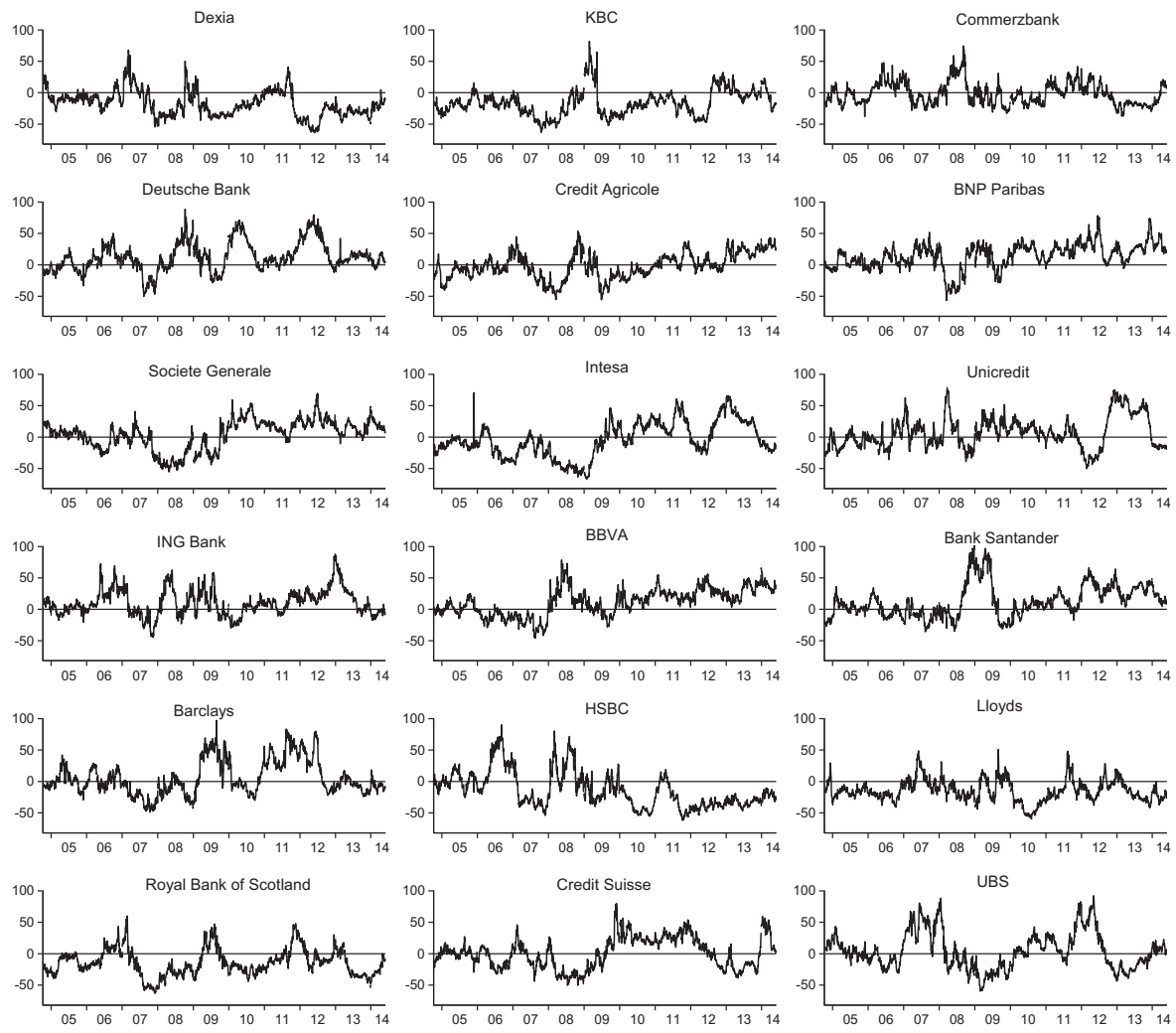

Figure 9 Net directional volatility connectedness of the EU FIs.

big German FIs circulated in the summer of 2008, its net-connectedness increased gradually to reach to $40 \%$ by the end of August. Following the collapse of Lehman, its net conectedness increased further to reach $88 \%$ by October 8 . From October to the end of February 2009, it fluctuated between $20 \%$ and $70 \%$. The third round of increases in Deutsche Bank's net-connectedness was due to the Greek debt crisis. From $-20 \%$ in October 2009 , it increased gradually to reach $70 \%$ by the end of April 2010. The fourth and final significant increase in Deutsche Bank's net-connectedness was following the news about the Libor fixing scandal in several countries. From 7\% in late-October 2011 its net-connectedness increase to 79\% by late-May 2012. In the end, Deutsche Bank accepted its involvement in the scandal in July 2012, and agreed in December 2012 to pay $\$ 725$ million in fines to the EU authorities. This was in addition to $\$ 351$ million that it was going to pay for the Tibor fixing scandal in Japan. Finally, the news that EU turned up pressure on FIs involved in the Libor fixing scandal led to a temporary jump of the net-connectedness to $42 \%$ between February 19 to 24, 2013. 
The fluctuations in the net volatility connectedness of Commerzbank were less pronounced and short-lived compared to those of the Deutsche Bank. Commerzbank's net-connectedness increased after the Fed's interest rate hike in 2006. Its net-connectedness increased to 50\% in May 2008 following the news about a possible merger of Commerzbank with Dresdner Bank and Post Bank as envisaged by the German FI regulators. Before its connectedness declined, the three-way merger deal was transformed into the debt-financed acquisition of Dresdner Bank by Commerzbank at the end of August, just 2 weeks before Lehman's collapse. With Lehman's collapse, Commerzbank ended up asking for help from the government. In December 2008, German government bailed out Commerzbank with a cash injection of $€ 18.2$ billion. Since the end of 2008, Commerzbank had been trying to deleverage. It has cut its assets by $26 \%$, from $€ 841$ billion at the end of 2009 to $€ 633$ billion as of the end of 2012 .

In the case of France, BNP Paribas and Societe Generale stocks play more important roles in determining the country's net-connectedness. This is even more true during the European sovereign debt and banking crisis. Both FIs had significant holdings of Greek government bonds, and their profits were hit by write-downs amounting to billions of euros related to Greek sovereign debt. They had sizable net-connectedness since 2010. Actually, they had both positive net-connectedness after 2009. Credit Agricole, on the other hand, had negative or close to zero netconnectedness from mid-2009 until the second-half of 2011. It moved to positive territory after the crisis was spread to Italy and Spain in the summer of 2011. Credit Agricole had to book $\mathrm{a} € 2$ billion net loss after selling Emporiki, its Greek banking subsidiary, for just $€ 1$ in mid-October 2012. Its net-connectedness stayed in the 20$40 \%$ range since the end of 2012. BNP Paribas experienced a sizable increase in its net-connectedness to 50\% in May 2007. Its net-connectedness stayed at that level for most part of 2007 especially during the liquidity crisis of July-August 2007.

Among the two Italian FIs, the net-connectedness of Unicredit fluctuated substantially over time. From the second half of 2006 to the Lehman's collapse in September 2008, its net-connectedness fluctuated within the $0-50 \%$ band. At the end of March 2008 (which coincides with the takeover of Bear Stearns by J.P. Morgan), Unicredit's net-connectedness reached as high as $80 \%$ for a brief period. Having negative net-connectedness after the collapse of Lehman Brothers, its netconnectedness moved to positive territory and fluctuated within the $0-40 \%$ band until the end of 2011. Since then it dived down to $-40 \%$ by the end of 2001 . However, following its attempts to raise capital at lower prices and the political uncertainty before the Italian general elections increased the net volatility connectedness of the stock all the way up to $75 \%$ by December 2012. Its net-connectedness finally came down in late 2013. This was a tough period for Unicredit during which many commentators were predicting the demise of the FI.

Intesa San Paolo's net-connectedness, on the other hand, fluctuated more widely than that of Unicredit. The stock experienced substantial degree of negative net-connectedness in 2006 and during the global financial crisis. With the European crisis, since 2010, its net-connectedness moved into positive territory and increased 
over time, reaching the highest level, $60 \%$, in the summer of 2011 . As a result of the political uncertainty before the general elections of 2013, the net-connectedness of Intesa increased to reach $66 \%$. Intesa net-connectedness declined over time gradually and finally moved to negative territory in late 2013. Our findings about the Italian FIs' contribution to the European-wide systemic risk is consistent with the findings of Blacket al. 2013), which showed that the marginal contribution of the Italian FIs to the systemic risk of the European banking industry increased significantly during the European debt and banking crisis, and in 2011 in particular.

Among the two Spanish FIs, BBVA's net-connectedness increased $48 \%$ on January 22, 2008. It increased further in the coming months, reaching as high $78 \%$ in mid-May 2008. Why did it increase? Its net-connectedness declined in August 2008. After a brief period in mid-2009, BBVA's net-connectedness has been positive all along, but it fluctuated with the $20-40 \%$ band for most of the time. Bank Santander, on the other hand, had its highest net-connectedness (95\%) in the aftermath of the Lehman bankruptcy for almost a year. During the European debt crisis, both FIs had positive net-connectedness, gradually increasing towards 2012 and 2013.

Among the four British FIs in our sample, Lloyds had lower net-connectedness compared to others. The increases in Lloyds' net-connectedness (in mid-2009, and in the summers of 2011 and 2012) were all short-lived compared to others. On August 4, 2011, trading in shares of Lloyds and Barclays was suspended as both FIs' stocks lost more than $£ 1$ billion in value. Volatility shocks to Barclays' stock, on the other hand, tend to generate substantial connectedness to others, as can be witnessed in Barclays' net-connectedness plot. Throughout 2009, its netconnectedness fluctuated between $60 \%$ and $100 \%$. Its net-connectedness increased again in early 2011 and stayed high until the second half of 2012.

The net volatility connectedness of HSBC followed quite a different path compared to that of Barclays. It was positive in 2006 following the Fed's decision to raise interest rates, but it reached to $40 \%$ at the maximum. During the U.S. financial crisis, its net-connectedness first increased closed to $70 \%$ at the end of 2007 and fluctuated in the $25-60 \%$ band throughout 2008 . Following the Lehman bankruptcy, its net-connectedness dropped to negative values, indicating that it was viewed as a safer FI at a time when the global financial system was in jeopardy. Since 2009, HSBC's net volatility connectedness mostly stayed in the negative territory.

RBS's net volatility connectedness increased in mid-2006 following the unwinding of the carry trades around the world. During the first phases of the U.S. financial crisis, however, RBS had a net volatility connectedness from others. While major U.S. FIs were announcing huge losses, RBS announced a profit of $£ 10$ billion in the fall of 2007. October 2007 proved to be the fateful month that sealed RBS's fate: despite signs of worsening in the UK banking sector (such as the liquidity problems faced by Northern Rock), RBS went ahead with the $£ 49$ billion takeover of ABN Amro, the biggest FI in the Netherlands 12 A year later, in October 2008,

\footnotetext{
${ }^{12}$ In September 2007, Northern Rock had suffered the first run on a British FI for more than 100 years, exposing the vulnerability of the UK FIs to the U.S. financial crisis.
} 
RBS sought for a multibillion pound bailout package from the UK government. On February 26, 2009, RBS announced the largest annual loss in UK corporate history of $£ 24.1 \mathrm{bn}$. Following the announcement, its net-connectedness jumped to reach $50 \%$. By the end of 2009, its net-connectedness declined and moved to the negative territory. However, its net-connectedness increased again in the summer of 2011. On August 5, 2011, trading in RBS shares was halted in order to stem the free fall in the share price. As downward move in RBS stock followed the moves in Barclays and Lloyds (both of which reached very high levels), RBS' net-connectedness stayed in the negative territory. However, as days went by, RBS's net-connectedness sharply increased to reach close to $57 \%$.

Finally, the Netherlands is represented by ING Bank, the largest FI in the country. ING Bank had sizable net volatility connectedness following the Fed's rate decision in May 2006, in the first half of 2008, throughout 2009 and in the second half of 2011. However, from the beginning of July 2012 its volatility connectedness increased substantially to reach the maximum level, 91\%, on December 14, 2012. ING Bank itself was not the source of the problem. The fourth largest FI of the Netherlands, SNS Reaal NV, went into serious trouble in the second half of 2012 and the beginning of 2013. In the end, the Dutch government decided to nationalize SNS Reaal NV on February 1, 2013. As a result, ING Bank's net volatility connectedness declined quickly and fell below $20 \%$ as of the end of our sample. Interestingly, during this period ING Bank was one of the FIs that generated very high net volatility connectedness to other FIs. As we have already discussed above, the two Italian FIs were the other FIs with increased connectedness during this period.

\section{PAIRWISE CONNECTEDNESS ON SOME CRITICAL DAYS}

So far we focused on the dynamics of connectedness across the Atlantic and across institutions over time. The analysis of the dynamic behavior helps to understand the developments in the financial markets over time. However, the connectedness framework is also very useful to understand how volatility connectedness across the FI stocks took place on some critical days. For that reason, in this section we focus on the connectedness on some chosen days during the U.S. financial crisis and the European debt and banking crisis.

We start with the build-up stage of the U.S. financial crisis and plot the volatility network plots on four particular days in 2007 in Figure 10 The days are chosen intentionally to show how the volatility connectedness intensified over time in the build up toward the liquidity crisis of 2007.

First tremors of the U.S. mortgage crisis were felt at the end of February and the first few days of March 2007. The connectedness index increased by 2-3 percentage points on March 1, 2007 (see Figure 10 ). A closer look at the resulting network plot on that day shows that UBS, Dexia, J.P. Morgan, and Morgan Stanley had the highest volatility connectedness to others on that day, followed by several U.S. 


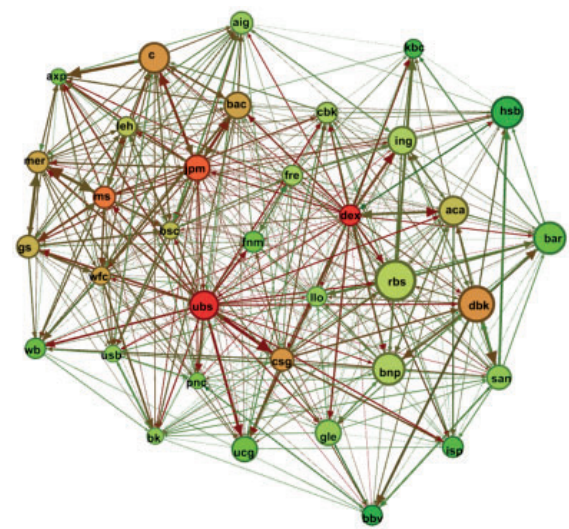

(a) March 1, 2007 (index $=82.5 \%$ )

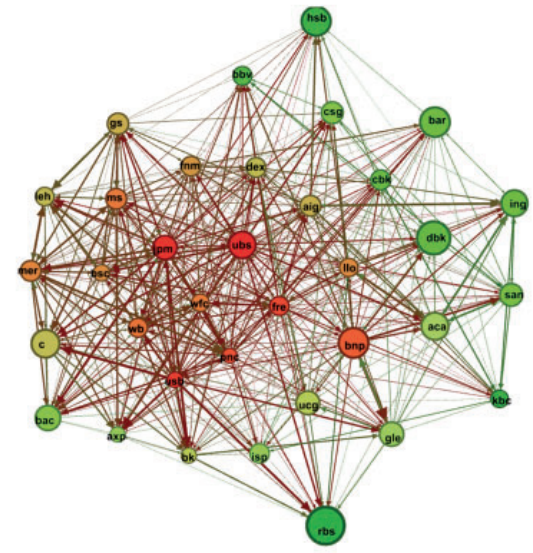

(c) August 1, 2007 (index $=85.4 \%$ )

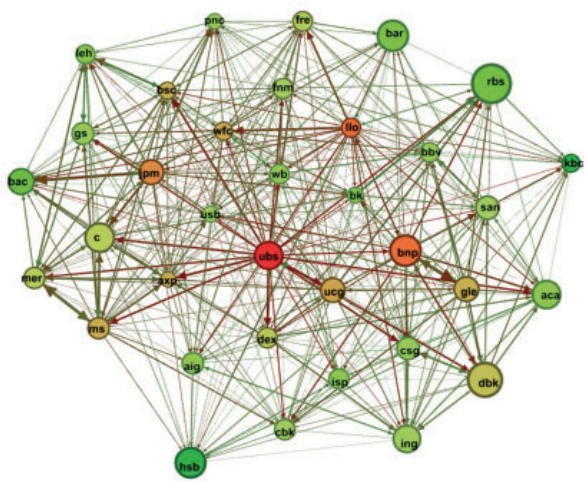

(b) June 7, 2007 (index $=81.0 \%$ )

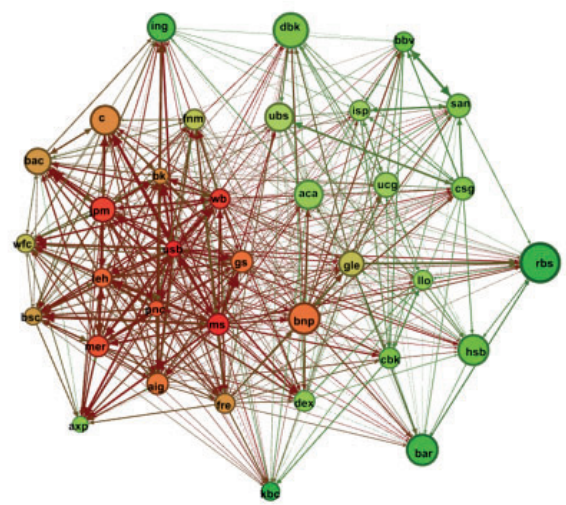

(d) October 22, 2007 (index $=88.4 \%$ )

Figure 10 Net pairwise connectedness—subprime and liquidity crises of 2007.

and European FIs. The early tremors did not generate a lasting impact and the connectedness index declined immediately back to its earlier levels.

In June, the markets started to rock again as it became apparent that U.S. and European FIs have invested directly or indirectly on U.S. subprime mortgage markets. In early June 2007, the connectedness index increased several percentage points to reach $81 \%$ by June 7 . The network graph on June 7 reveals that at the center was UBS, rather than Bear Stearns, whose hedge funds were having trouble on those days (see Figure 10b). Lloyds, BNP Paribas, and JPM among others were distant followers.

In the last week of July 2007, the U.S. mortgage crisis turned into a liquidity crisis that hit major FIs on both sides of the Atlantic. Accomplishing the biggest jump in its history, the connectedness index increased from $80.9 \%$ on July 25 to 
85.4\% on August 1, 2007. The network graph for August 1, 2007 (see Figure 10k) shows that four U.S. FIs (JPM, USB, PNC, FRE, as indicated by the black (red) colored nodes) started to generated very high volatility connectedness to others, and including their counterparts on the other side of the Atlantic. Six other U.S. FIs (WFC, WB, BSC, MER, MS, and FNM) also generate high volatility connectedness to others, as indicated by the dark gray (brown) color of their nodes. On the European side, UBS, BNP, and Lloyds continued to suffer from high volatility and generate volatility connectedness to others.

The index continued to increase mostly because the market continued to receive bad news from the U.S. FIs. In October 2007, all major FIs revealed billions of dollars losses from their investments in the U.S. subprime mortgages and their derivatives 13 As a result their stocks got a hit. They started to generate volatility connectedness to each other and their European counterparts. This is clearly visible in our volatility network plot for October 22, 2007 (see Figure 10d). The edges between the U.S. FI stocks became thicker. Nodes for all major U.S. FIs started to have black or dark gray (red or brown) colors indicating that they have the highest directional connectedness others. All European FIs (with the exception of BNP Paribas and Societe Generale) were on the receiving end, as indicated by their light gray (green) colored nodes. In the meantime, the divide between the U.S. and European FIs becomes slightly more visible in the plot for October 22, 2007.

In Figure 11 we present the connectedness plots on 4 days in the first half of 2008. Each day signifies an upward move in the total connectedness index. We have already seen above that on January 22, 2008, along with the FOMC's unscheduled meeting the index jumped from $84.8 \%$ to $88.5 \%$. The Fed's action appeared to be prompted by turmoil in international equity markets. While Americans were on holiday Monday and still asleep Tuesday morning, UK's FTSE 100 index fell $5.5 \%$ and Japan's Nikkei 225 lost $8.7 \%$. Indian stocks fell so quickly that the Bombay Stock Exchange halted trading. The volatility network plot on January 22 shows that UBS was the FI with the highest connectedness to others, especially to European FIs (see Figure 11]). Its net-connectedness on January 22 was $63 \%$. On the European side, BBVA, HSBC, Lloyds followed UBS. On the U.S. side, Bancorp, Bear Stearns, Citigroup, Lehman Brothers had high connectedness to others.

The index continued its upward move slowly in the days and weeks to come. On February 13, it was equal to $89.1 \%$. UBS was still at the center of the volatility network (see Figure 11b). Consistent with the increase, the North Atlantic FI volatility network was becoming tighter. Other major U.S. FIs (Bank of America, J.P. Morgan, Wells Fargo, PNC, and Morgan Stanley) started to have higher to-connectedness as well. As a comparison of the February 13 network plot with that of January 22, the pairwise connectedness among the U.S. FIs increased significantly.

In early March 2008, rumors about Bear Stearns' viability was percolating the markets, putting its stock under enormous pressure. Its net-connectedness

\footnotetext{
${ }^{13}$ As of mid-November 2007 , the subprime losses were expected to reach $\$ 400$ billion.
} 


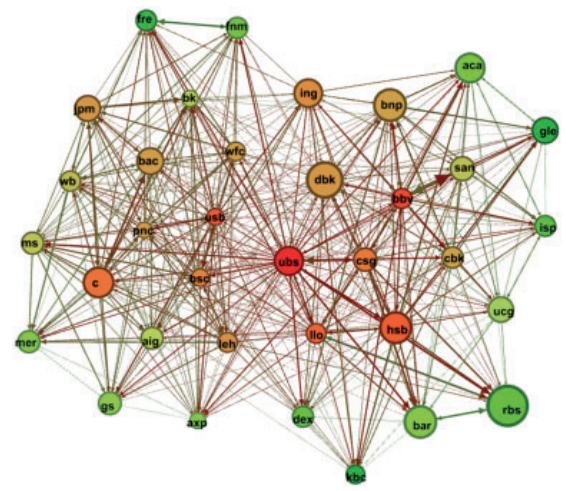

(a) January 22, 2008 (index $=88.5 \%$ )

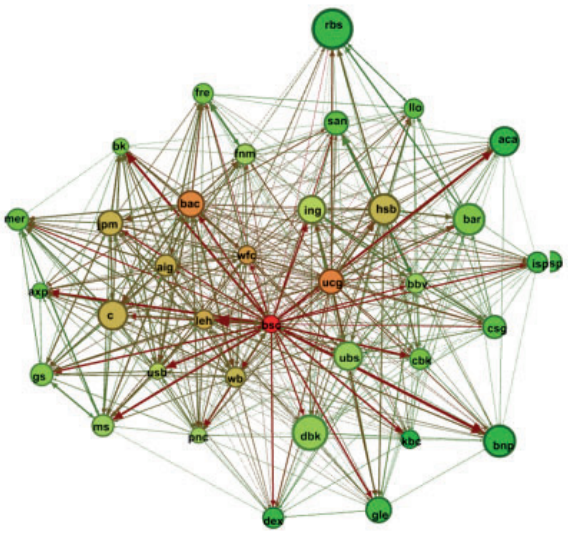

(c) March 17, 2008 (index=90\%)

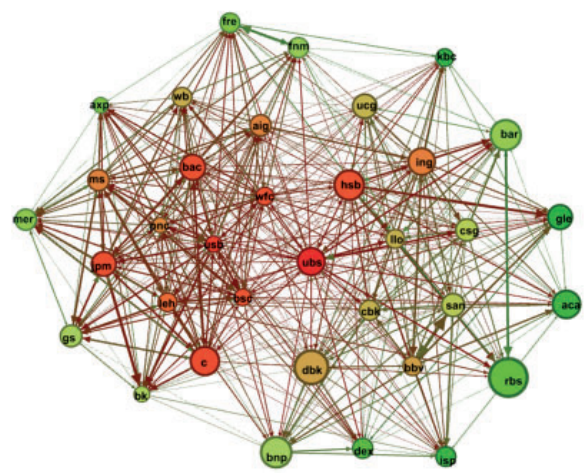

(b) February 13, 2008 (index $=89.1 \%$ )

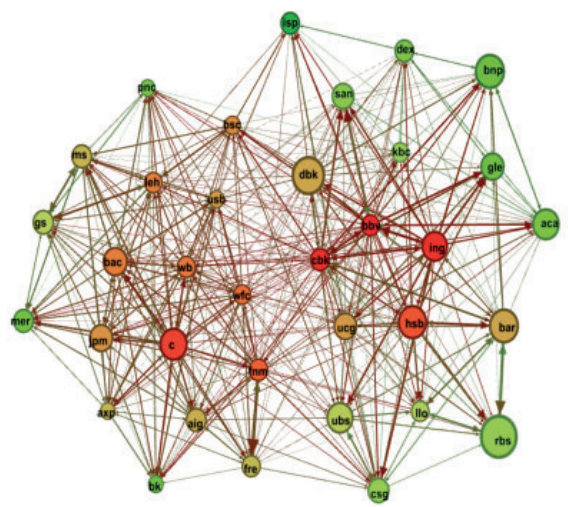

(d) May 30, 2008 (index $=86.6 \%$ )

Figure 11 Net pairwise connectedness-first half of 2008.

increased to $54 \%$ on March 13, then to $69 \%$ on March 14 . On March 17, 2008, Bear Stearns moved to the center of volatility network graph generating connectedness to all other FIs on both sides of the Atlantic (see Figure 11k). Its net-connectedness was $126 \%$. The same day the Federal Reserve Bank of New York arranged the takeover of the FI by J.P. Morgan. Its most significant pairwise-connectedness was with Lehman Brothers.

Bear Stearns' stock ceased to be traded on May 30, 2008. The FI volatility network plot on that is presented in Figure $11 \mathrm{~d}$. The index is lower $(86.6 \%)$ than the levels in other 3 days covered in Figure 11 Furthermore, on that day, the toconnectedness measures of three European FIs, Commerzbank, BBVA, and ING bank, were quite high, followed by Citigroup and HSBC. It is also important to note that Fannie Mae and Wells Fargo moved closer to the European FIs. We have already discussed the case of Commerzbank. News about its merger with Dresdner 


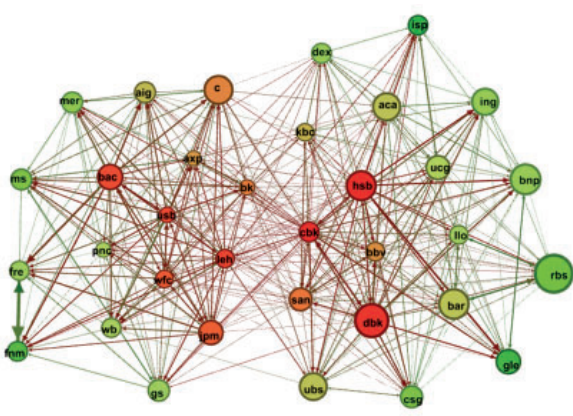

(a) September 1, 2008 (index $=88.0 \%$ )

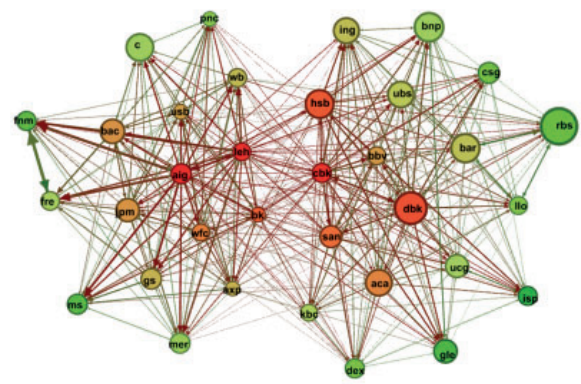

(c) September 15, 2008 (index $=88.9 \%$ )

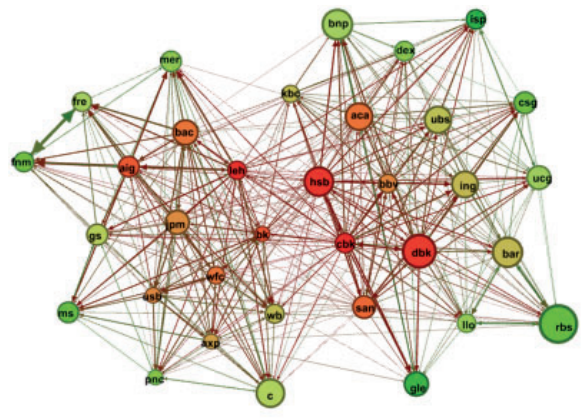

(b) September 12, 2008 (index $=88.4 \%$ )

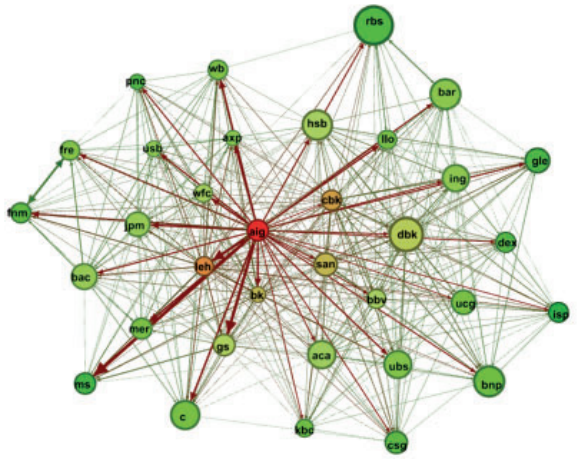

(d) September 19, 2008 (index=89.8\%)

Figure 12 Net pairwise connectedness—Lehman bankruptcy.

Bank and Post Bank pushed by the German bank regulator increased the volatility of the stock and it mostly affected Deutsche Bank, the only other German FI in our sample.

Next, we have a closer look at the net pairwise volatility connectedness immediately before and after the collapse of Lehman Brothers on September 15, 2008. The collapse of Lehman Brothers was important because it was the event that transformed the U.S. financial crisis into a global one. In Figure 12 we present the connectedness plots on 4 days $(1,12,15$, and 19) in September 2008. On each of those 4 days the total connectedness was at or above $88 \%$, closer to the peak. In the first three graphs, the divide between the U.S. and the European FI stocks is quite visible. The within-continent pairwise volatility connectedness was stronger than the one across the Atlantic. Except for September 19, Lehman was always in the red, with increasing thickness of edges to other U.S. FIs. Even though AIG was further away from Lehman on September 1, it moved closer on September 12 and the closest to Lehman on September 15, the day Lehman's bankruptcy was announced. Then, on September 19, AIG moved to the center stage, with a black (red) node and thick 


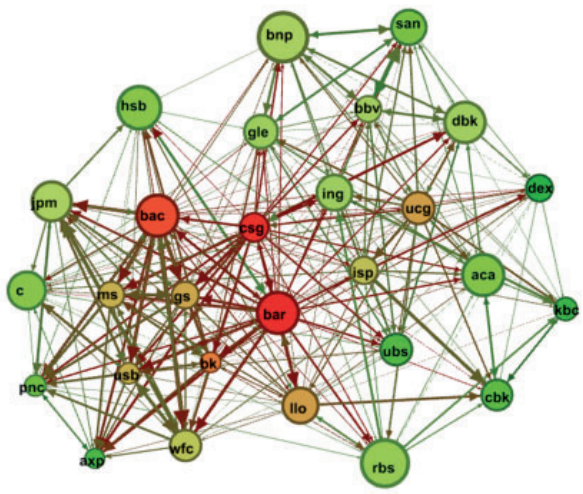

(a) November 12, 2009 (index=77.3\%)

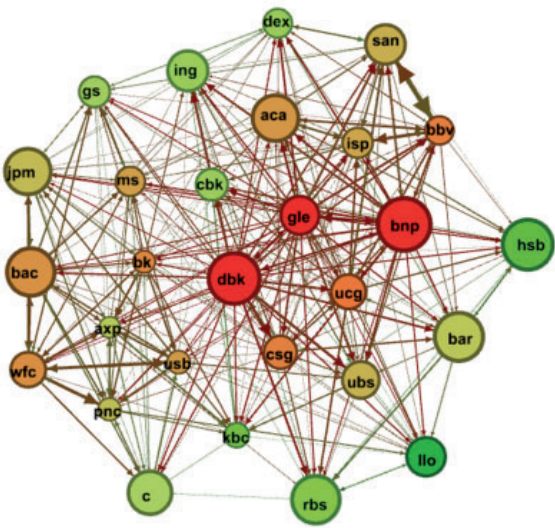

(c) May 6, 2010 (index=87.6\%)

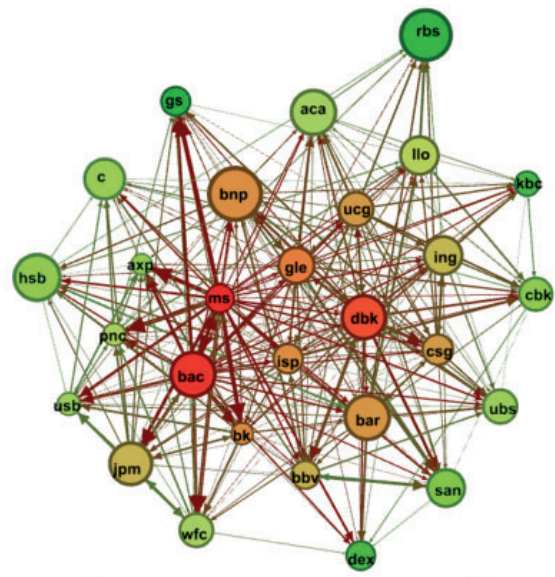

(b) December 29, 2009 (index=84\%)

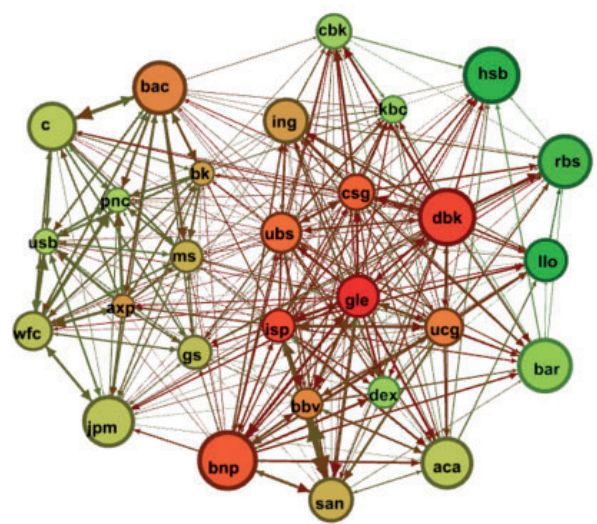

(d) July 19, 2010 (index $=88.9 \%$ )

Figure 13 Net pairwise connectedness-Greek crisis.

edges connecting it to all other stocks. The Atlantic divide between the U.S. and European FIs disappeared. All other FI stocks were on the receiving end, indicated by the mostly light gray (green) colored nodes in the plot. The edges froom AIG to some U.S. FIs, such as Merrill Lynch, Morgan Stanley, J.P. Morgan, Goldman Sachs, and Lehman were very thick, but the edges from AIG to European FIs were now thicker as well.

After the Lehman bankruptcy, the U.S. financial crisis was spread around the world, but most notably to the European continent. Even though all European countries were badly hit by the shocks emanating from the U.S. financial system, peripheral EU member countries such as Ireland, Portugal, and Greece suffered 


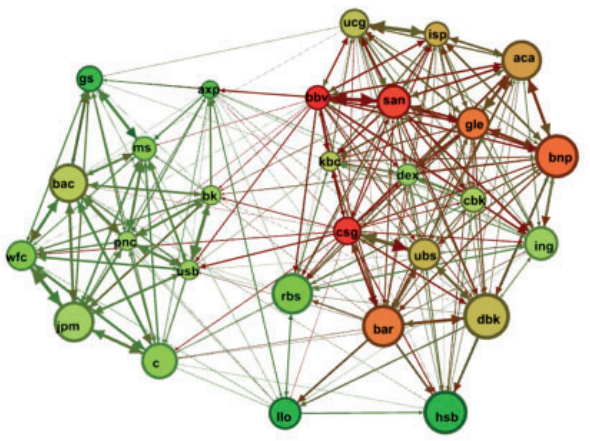

(a) June 10, 2011 (index $=75.7 \%$ )

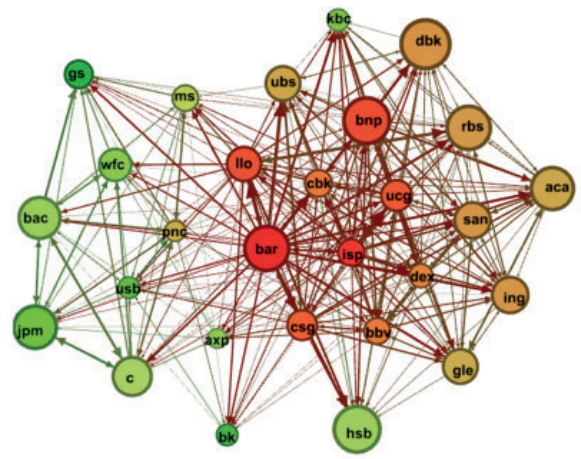

(c) August 12, 2011 (index $=87.6 \%$ )

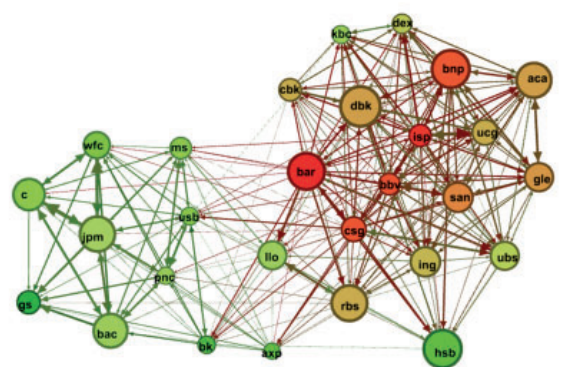

(b) July 21, 2011 (index $=80.2 \%$ )

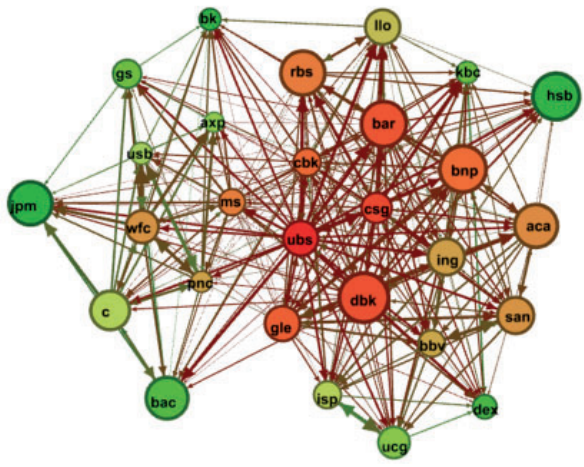

(d) December 29, 2011 (index=89\%)

Figure 14 Net pairwise connectedness-Italian/Spanish crisis.

the most. In particular, the fiscal calamities of the Greek economy had become evident in late 2009. From the end of 2009 through May 2010, the state of the Greek economy and its financial system worsened day by day. In the mean time, the EU could not come up with a policy that would address the major issues facing the Greek economy. In the next graph, we plot the net pairwise volatility connectedness among the U.S. and European FIs on 4 days during the first phase of the Greek debt crisis, namely, on November 12 and December 29, 2009, and May 6 and July 19, 2010.

Above we have already provided information about how the Greek debt crisis was allowed to become such a major headache for the EU. As the EU leaders dragged their foot in coming up with a viable solution to address the troubles facing Greece in the first half of 2010, the markets had become quite jittery about the possibility of the contagion of the crisis to other countries. The connectedness index started to increase in April to reach 87.6\% on May 6, 2010. On that day, three Euroepan FIs, 
Deutsche Bank, BNP Paribas, and Societe Generale, which were heavily exposed to Greek public and private debt generated connectedness to each other as well as other FIs.

As we highlighted above, the meeting of the EU leaders did not produce a real solution to the Greek debt crisis and hence the connectedness continued to increase in the summer months to reach $88.9 \%$ on July 19, 2010. Again Societe Generale, Deutsche Bank, and BNP Paribas were among the FIs that generated connectedness to others.

Finally, we have a closer look at the net pairwise volatility connectedness across the U.S. and the European FIs during the second half of 2011, a period during which Italy and Spain were caught in the whirlwind of the the Euro debt and banking crisis. In Figure 14 we present the connectedness plots on June 10, July 21, August 12 and December 29. On June 10 and July 21, the U.S. FIs were all on the receiving end, while mainly Spanish (BBVA and Santander) and Italian as well as French and British FIs were transmitting shocks to other FIs. The total connectedness index was relatively low, $75.7 \%$ and $80.2 \%$ on the two days, respectively. While the Atlantic divide between the two "continents" was wide open on June 10, it became slightly tilted as shocks emanating from several European FIs started to have an impact on Bank of New York and American Express Bank.

The situation worsened on August 12 as the total connectedness index increased further to reach $87.6 \%$. With the exception of HSBC and KBC, all European FIs were generating volatility connectedness to each other and the American FIs. In particular, British FIs, in whose stocks trading were suspended in early August, were among the most significant generators of volatility connectedness to other FIs, including American FIs. Lloyds and, in particular, Barclays moved to the center of network plot on August 12. By the end of the year, the volatility connectedness among the European FIs continued to be high.

\section{CONCLUDING REMARKS}

Within a year after its outbreak, the U.S. subprime mortgage crisis of 2007 was transformed into a global financial crisis, with serious long-run effects on the global capitalist system. In 2009, the crisis moved across the Atlantic, with devastating effects on European FIs and governments. As in other crises before, during the global financial crisis and the European banking and sovereign debt crisis volatility shocks spread quite rapidly across individual assets, markets and countries connecting them in a state of high volatility.

In this article, we used the Diebold-Yilmaz connectedness framework to study the volatility connectedness of major FIs across the Atlantic. It allowed us to understand how each individual FI contributed to the total volatility connectedness. In addition, given that there are many FIs that need to be included in the analysis, we aggregated the individual FI effects at the country level and analyze how the volatility shocks in one or several countries affect the major FIs in other countries. 
We obtained several important results from the analysis of the volatility connectedness of major FIs. We were able to match the behavior of the connectedness measures over time with the major developments that affected individual FI stocks as well as the whole banking systems of the countries in our sample. Perhaps our most important result concerns the dynamics of directional volatility connectedness for FIs across the Atlantic. Until the collapse of Lehman Brothers, the direction of volatility connectedness was from the U.S. FIs to European FIs. But once Lehman Brothers went bankrupt in mid-September 2008, the financial crisis was transformed into a global one, and the volatility connectedness across the Atlantic became bidirectional, with the net-connectedness from the U.S. to Europe declining significantly. Then from late 2010 onward, the net-connectedness from the U.S. to Europe became negative, as the sovereign debt and banking crises intensified in the EU periphery-all European FIs suffered from high volatility and spread that volatility to their counterparts in the United States.

Received January 2, 2015; revised October 7, 2015; accepted October 7, 2015.

\section{REFERENCES}

Acharya, V., L. Pedersen, T. Philippe, and M. Richardson. 2010. “Measuring Systemic Risk." Manuscript, New York University.

Adrian, T. and M. Brunnermeier. 2008. "CoVaR." Staff Report 348, Federal Reserve Bank of New York.

Alizadeh, S., M. W. Brandt, and F. X. Diebold. 2002. Range-Based Estimation of Stochastic Volatility models. Journal of Finance 57:1047-1091.

Andersen, T. G., T. Bollerslev, P. F. Christoffersen, and F. X. Diebold. 2013. “Risk Measurement for Market Risk Management." In M. Harris, G. Constantinedes and R. Stulz (eds.), Handbook of the Economics of Finance, Volume 2, Part B, Elsevier, 1127-1220.

Andersen, T. G., T. Bollerslev, F. X. Diebold, and P. Labys. 2003. Modeling and Forecasting Realized Volatility. Econometrica, 71:579-625.

Billio, M., M. Getmansky, A. W. Lo, and L. Pelizzon. 2012. Econometric Measures of Connectedness and Systemic Risk in the Finance and Insurance Sectors. Journal of Financial Economics 104:535-559.

Black, L., R. Correa, X. Huang, and H. Zhou. 2013. "The Systemic Risk of European Banks during the Financial and Sovereign Debt Crises." Manuscript, Federal Reserve Board, Washington, D.C.

Bonaldi, P., A. Hortaçsu, and J. Kastl. 2015. "An Empirical Analysis of Funding Cost Spillovers in the Euro-zone with Application to Systemic Risk." Manuscript, University of Chicago.

Diebold, F. X. and K. Yilmaz. 2009. Measuring Financial Asset Return and Volatility Spillovers, with Application to Global Equity Markets. Economic Journal 119:158-171. 
Diebold, F. X. and K. Yilmaz. 2012. Better to Give than to Receive: Predictive Measurement of Volatility Spillovers (with discussion),. International Journal of Forecasting 28:57-66.

Diebold, F. X. and K. Yilmaz. 2014. On the Network Topology of Variance Decompositions: Measuring the Connectedness of Financial Firms. Journal of Econometrics 182:119-134.

Diebold, F. X. and K. Yilmaz. 2015. Financial and Macroeconomic Connectedness: A Network Approach to Measurement and Monitoring. Oxford University Press.

Engle, R. F. and B. T. Kelly. 2012. Dynamic Equicorrelation. Journal of Business and Economic Statistics 30:212-228.

Garman, M. B. and M. J. Klass. 1980. On the Estimation of Security Price Volatilities From Historical Data. Journal of Business 53:67-78.

Koop, G., M. H. Pesaran, and S. M. Potter. 1996. Impulse Response Analysis in Nonlinear Multivariate Models. Journal of Econometrics 74:119-147.

Liu, L. 2015. Ph.D Dissertation in Progress, University of Pennsylvania.

Pesaran, H. H. and Y. Shin. 1998. Generalized Impulse Response Analysis in Linear Multivariate Models. Economics Letters 58:17-29.

Tibshirani, R., M. Saunders, S. Rosset, J. Zhu, and K. Knight. 2005. Sparsity and Smoothness via the Fused Lasso. Journal of the Royal Statistical Society, Series B. 67:91-108. 